\title{
Reconstructing Flood Events in Mediterranean Coastal Areas Using Different Reanalyses and High-Resolution Meteorological Models
}

\author{
A. SENATORE \\ Department of Environmental Engineering, University of Calabria, Rende, Italy \\ S. DAVOLIO \\ Institute of Atmospheric Sciences and Climate, CNR-ISAC, Bologna, Italy \\ L. FuRnARI AND G. MENDICINO \\ Department of Environmental Engineering, University of Calabria, Rende, Italy
}

(Manuscript received 19 November 2019, in final form 26 June 2020)

\begin{abstract}
Reliable reanalysis products can be exploited to drive mesoscale numerical models and generate highresolution reconstructions of high-impact weather events. Within this framework, regional weather and climate models may greatly benefit from the recent release of the ERA5 product, an improvement to the ERA-Interim dataset. In this study, two different convection-permitting models driven by these two reanalysis datasets are used to reproduce three heavy precipitation events affecting a Mediterranean region. Moreover, different sea surface temperature (SST) initializations are tested to assess how higher-resolution SST fields improve the simulation of high-impact events characterized by strong air-sea interactions. Finally, the coupling with a distributed hydrological model allows evaluating the impact at the ground, specifically assessing the possible added value of the ERA5 dataset for the high-resolution simulation of extreme hydrometeorological events over the Calabria region (southern Italy). Results, based on the comparison against multiple-source precipitation observations, show no clear systematic benefit to using the ERA5 dataset; moreover, intense convective activity can introduce uncertainties masking the signal provided by the boundary conditions of the different reanalyses. The effect of the high-resolution SST fields is even more difficult to detect. The uncertainties propagate and amplify along the modeling chain, where the spatial resolution increases up to the hydrological model. Nevertheless, even in very small catchments, some of the experiments provide reasonably accurate results, suggesting that an ensemble approach could be suitable to cope with uncertainties affecting the overall meteo-hydrological chain, especially for small catchments.
\end{abstract}

\section{Introduction}

Unique morphological characteristics make the Mediterranean basin prone to natural hazards related to the water cycle (Flaounas et al. 2019), in particular during autumn when the air-sea thermal contrast becomes remarkable. Steep slopes in the vicinity of coastal areas, and the Mediterranean Sea itself, which acts as a large source of moisture and heat, instigate rapid uplift of moist, unstable air, responsible for triggering condensation and convective instability processes (Ducrocq et al. 2014). Therefore, the Italian peninsula, surrounded

Corresponding author: Alfonso Senatore, alfonso.senatore@ unical.it by the Mediterranean Sea, with very urbanized littorals characterized by steep-sided valleys in coastal complex terrain, is prone to intense weather phenomena and particularly exposed to severe hydrogeological consequences (Polemio and Petrucci 2012). An analysis of damaging hydrogeological events affecting the Calabria region throughout 92 years of observations highlighted that rainfall-induced landslides, floods, and flash floods mainly affect the eastern side of the region (Aceto et al. 2016). Indeed, heavy persistent rainfall is a frequent threat for Calabria, the southernmost tip of the peninsula; recent severe precipitation events there have been deeply studied (Federico et al. 2008; Chiaravalloti and Gabriele 2009; Senatore et al. 2014; Gascòn et al. 2016; Avolio et al. 2019). Whether classified as short-lived or 
long-lived events (Avolio and Federico 2018), these events produced devastating floods in a few hours (Llasat et al. 2013), largely because of orographic forcing. The complex, steep orography creates a local-scale forcing that scales up to the mesoscale, thus causing rapid variability of wind and precipitation fields, particularly difficult to predict with numerical weather prediction (NWP) models. The problem is even more complex due to other factors, such as the turbulent nature of convection, or cloud and precipitation microphysics, which can turn a simple deep convective event into an extreme event causing flooding.

The accurate quantitative precipitation forecasting (QPF) in complex orography remains one of the biggest challenges for meteorological modeling (Richard et al. 2007). However, it is important to continue improving forecasting of heavy precipitation events, to reduce uncertainties of regional climate projections, and to understand better the physical mechanisms causing heavy precipitation. NWP models represent a sophisticated tool suitable to address these issues and high spatial resolution is required to avoid convective parameterization, a known source of error (Khodayar et al. 2016). Convection-permitting models explicitly resolve deep convection and provide a more accurate description of severe weather at both meteorological (Mass et al. 2002; Schwartz et al. 2009; Clark et al. 2016) and climatological scales (Grell et al. 2000; Prein et al. 2015), including downscaling applications (Pontoppidan et al. 2017; Coppola et al. 2018). Moreover, the high-resolution and the increased capability of models in representing relevant physical processes, have improved rainfall forecast skills (Weusthoff et al. 2010; Bauer et al. 2011), especially at the small scales particularly relevant for hydrological applications in coastal areas. Notwithstanding the rapid improvement of global NWP accuracy and the related efforts for detailed representation of hydrological processes (Zsoter et al. 2019), currently, at such scales, only an approach based on the convection-permitting resolution can address the challenge of multipurpose coupled meteorological-hydrological simulation systems (Fiori et al. 2014; Yucel et al. 2015; Davolio et al. 2015; Verri et al. 2017; Avolio et al. 2019; Senatore et al. 2020; Li et al. 2020).

Within this scientific framework, two different mesoscale modeling systems have been implemented in order to reconstruct some high-impact weather events that recently affected southern Italy, specifically, a highly convective summer event (11-12 August 2015), a stratified/orographic rainfall autumn event (31 October 2015-2 November 2015), and a fairly localized autumn event (24-26 November 2016). The aim is to evaluate the capability of high-resolution models to correctly reproduce these extreme events and the associated hydrological response. Since the European Centre for Medium-Range Weather Forecasts (ECMWF) has recently released the new climate reanalysis product ERA5 (Hersbach and Dee 2016), a dynamical downscaling exercise has been performed starting the mesoscale models from two different datasets of global reanalyses currently available, ERA-Interim (Dee et al. 2011) and ERA5. Then, the coupling with a distributed hydrological model allows evaluating the effects at the ground in terms of discharge in some affected basins. This approach has several goals: 1) it provides a benchmark for hydrometeorological forecasting of such events (hazard prediction), since it employs global reanalysis data to drive state-of-the-art convectionpermitting simulations; 2 ) it provides an evaluation of a modeling tool that can be applied for climate dynamical downscaling, not only for past events, but also for future scenarios; 3) it provides a quantitative evaluation of potential benefits of new reanalysis products for the reconstruction of extreme meteorological events; 4) it allows investigation of the contribution of some physical mechanisms, such as the sea surface temperature (SST). In particular, the latter point has been tested using highresolution SST data to initialize additional modeling experiments. The use of two different modeling systems allows assessing the robustness of the results in terms of the impact of reanalysis datasets and the performance of the downscaling procedure. The developed tool can be relevant to prevent and reduce the damages to the society and to the territory and to study and adopt structural measures. Moreover, the same setup can be easily applied also to drought and water resource availability.

The paper is organized as follows: section 2 describes the area of interest, the available data, and the modeling tools. Section 3 briefly presents the three severe weather events. The analysis of meteorological results is presented in section 4, while the cascading effects on hydrology are discussed in section 5 . Conclusions are drawn in section 6 .

\section{Data and methodology}

\section{a. Area of interest and observational datasets}

The study simulates events in the Calabria region of southern Italy (Fig. 1a). Calabria is characterized by complex and steep orography and is almost surrounded by the sea: the Tyrrhenian Sea to the west and the Ionian Sea to the south and east. The sharp transition from the sea to the land and the mountain play key roles in triggering intense precipitation events (Federico et al. 2003; Gascòn et al. 2016; Avolio and Federico 2018). Under favorable synoptic conditions, air further moistened by 

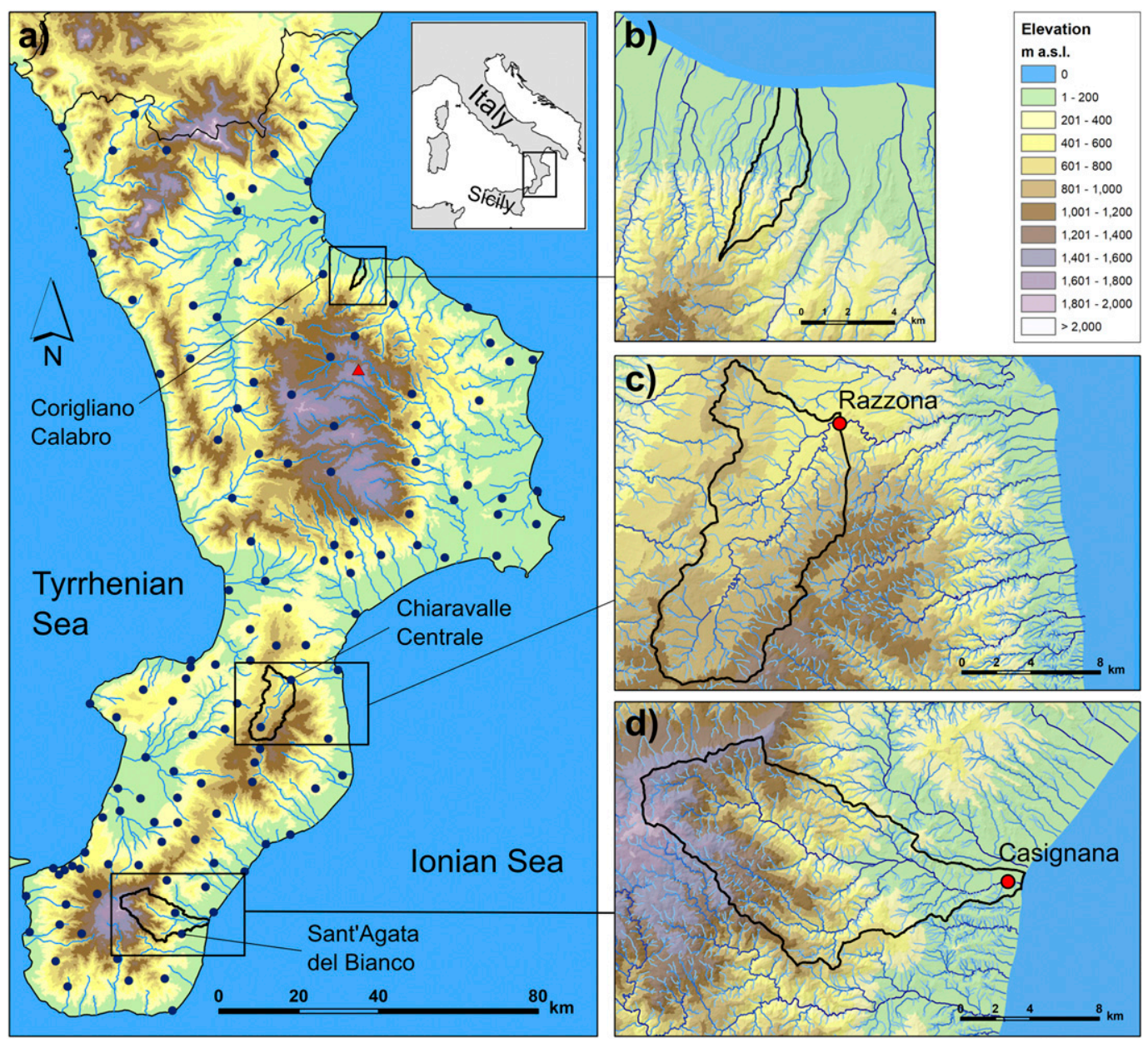

FIG. 1. Study area: (a) the Calabria region. Blue dots represent rain gauges in the regional monitoring network, the red triangle indicates the location of the C-band polarimetric Doppler weather radar. (b) Citrea Creek catchment; (c) Ancinale River catchment; (d) Bonamico Creek catchment.

atmosphere-sea exchanges is driven toward the region, impinging the southern Apennines chain whose elevation exceeds $1500 \mathrm{~m}$ in several areas and $2000 \mathrm{~m}$ locally. The direct orographic uplift or the interaction with the mountains may trigger and sustain precipitation even longer than one day over the same area, locally enhancing intensity. Densely populated regions along the coast, with many urban areas in the proximity of river outlets, pose challenges for civil protection.

Three catchments are used to evaluate simulated hydrological impacts. The first convective summer event affected only a few very small coastal streams, the most important of which is Citrea Creek (Fig. 1b), with a catchment area of $11.4 \mathrm{~km}^{2}$ and elevation ranging from the coast to $790 \mathrm{~m}$ MSL. Unfortunately, neither discharge data nor water level data are available for this stream. Although with different intensities, the two autumn events affected about all the eastern (Ionian) river catchments of the region. Among them, the Ancinale River and Bonamico Creek are selected since they are representative of the most impacted coastal areas. These catchments are two of the biggest in the region with available water level observations. Specifically, the Ancinale River catchment, ending at the Razzona gauging station, has an area of $116 \mathrm{~km}^{2}$ with elevation ranging from 1396 to $524 \mathrm{~m}$ MSL. (Fig. 1c), while the extension of the Bonamico Creek catchment closed at the Casignana gauging station (Fig. 1d) is $138 \mathrm{~km}^{2}$ (from 1900 down to $12 \mathrm{~m} \mathrm{MSL}$ ).

Water level data for the Ancinale River and the Bonamico Creek, as well as rainfall data from the regional weather monitoring network (Fig. 1a), are provided by the Calabrian Regional Agency for the Protection of the Environment. Such ground-based data are integrated by observations from a C-band polarimetric Doppler weather radar managed by the Italian National Civil Protection (Fig. 1a). Observational hourly 


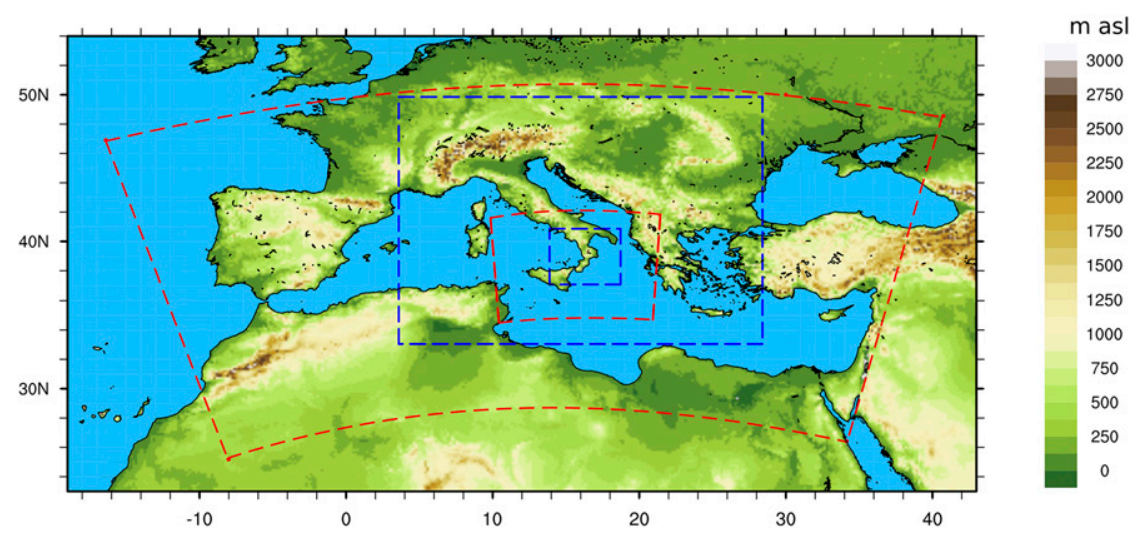

FIG. 2. Outer and inner integration domains for WRF (blue dashed lines) and BOLAMMOLOCH (red dashed lines) simulations.

rainfall fields are obtained by merging hourly groundbased rainfall observations with hourly radar data estimates, following Sinclair and Pegram (2005).

\section{b. Reanalysis and SST datasets}

High-resolution meteorological simulations are performed with two different mesoscale models, both driven by two reanalysis datasets, ERA-Interim and ERA5, that provide initial and boundary conditions (hereafter ICs and BCs, respectively). Both global datasets are produced by the ECMWF and have been implemented starting from 2006 and 2016, respectively. ERA-Interim covers the period from 1979 to 31 August 2019. The horizontal resolution is $0.75^{\circ}$, with 60 vertical levels from the surface to $0.1 \mathrm{hPa}$; data are available every $6 \mathrm{~h}$. The new reanalysis ERA5 comes not only with higher spatial $\left(0.25^{\circ}\right.$ and 137 hybrid sigma-pressure levels up to $0.01 \mathrm{hPa}$ ) and temporal resolution (hourly), but also with a much improved forecast model and an updated data assimilation system based on $4 \mathrm{D}-\mathrm{Var}$, exploiting more extensive observational inputs (Hennermann and Berrisford 2018). Therefore, a better representation of several tropospheric processes has been attained. As of October 2019, ERA5 reanalyses are available from 1979, but will eventually cover the time period from 1950.

In addition to the SST field provided by the reanalysis, mesoscale models are also initialized using a high-resolution $(2.2 \mathrm{~km})$ SST dataset, namely, the Medspiration L4 Ultrahigh Resolution SSTfnd, provided by the Medspiration Project (Merchant et al. 2008; Robinson et al. 2012) by Institut Français de Recherche pour l'Exploitation de la Mer (IFREMER)/Centre ERS d'Archivage et de Traitement (CERSAT) every $24 \mathrm{~h}$.

\section{c. Mesoscale and hydrological models}

Two different NWP provide simulations of the three heavy precipitation events. The first set of meteorological simulations is based on the Advanced Research Weather Research and Forecasting (WRF-ARW; Skamarock et al. 2008) Model version 3.7.1 used in two one-way nesting domains (Fig. 2). The WRF Model is a widely used, fully compressible, and nonhydrostatic model that allows many options for physical parameterizations. The WRF configuration selected in this study is the same used by Senatore et al. (2014) (Table 1).

The second set of meteorological simulations is based on the nonhydrostatic, fully compressible, convectionpermitting model MOLOCH (Modello Locale in Hybrid Coordinates; Malguzzi et al. 2006; Buzzi et al. 2014; Davolio et al. 2017), employed in cascade (one-way nesting) with the hydrostatic BOLAM (Bologna Limited Area Model; Buzzi et al. 2003) model. BOLAM and MOLOCH configurations are shown in Table 1. Model integration domains are shown in Fig. 2.

For each event, four numerical experiments are performed with both WRF and MOLOCH models, using different ICs and BCs (ERA-Interim and ERA5) and SST analysis (Table 1). Initialization times and simulation ranges are selected in order to cover the entire rainfall event. Details of each simulation are provided in Table 2.

The hydrological impact of the precipitation fields provided by both WRF and MOLOCH mesoscale models is simulated by the WRF-Hydro modeling system, version 3.0 (Gochis et al. 2015). Even though WRFHydro can be two-way coupled to WRF (e.g., Senatore et al. 2015), the modeling chain set up for this study allows one-way coupling with both WRF and MOLOCH. The distributed output of the atmospheric models drives at an hourly time step the WRF-Hydro land surface model (which is the Unified Noah, consistently with the WRF parameterization). The active modules are those related to subsurface, surface and channel water routing, which are performed at a horizontal resolution of $200 \mathrm{~m}$. 
TABLE 1. Main WRF and BOLAM/MOLOCH model setup and configuration.

\begin{tabular}{|c|c|}
\hline \multicolumn{2}{|c|}{ Main mesoscale model options } \\
\hline WRF & BOLAM/MOLOCH \\
\hline Resolution: $10 \mathrm{~km}$ (D01), $2 \mathrm{~km}$ (D02) & Resolution: 8 km (BOLAM), 2 km (MOLOCH) \\
\hline Grid points: $187 \times 205$ (D01), $200 \times 200(\mathrm{D} 02)$ & Grid points: $514 \times 306($ BOLAM), $482 \times 410($ MOLOCH) \\
\hline Vertical layers: 44 (D01, D02) & Vertical layers: 60 (both) \\
\hline Soil layers: 4 (D01, D02) & Soil layers: 7 (both) \\
\hline Time step: $60 \mathrm{~s}$ (D01), 12s (D02) & Time step: $60 \mathrm{~s}$ (BOLAM), 30s (MOLOCH) \\
\hline Microphysics: Purdue Lin (Chen and Sun 2002) & Radiation: Ritter and Geleyn (1992) and Morcrette et al. (2008) \\
\hline Cumulus: Kain-Fritsch (Kain 2004), only D01 & Turbulence: $E$-l 1.5 -order closure (Zampieri et al. 2005) \\
\hline Shortwave radiation: Dudhia (Dudhia 1989) & Soil processes and microphysics (Buzzi et al. 2014) \\
\hline Longwave radiation: RTTM (Mlawer et al. 1997) & SST boundary conditions: slab-ocean model (Davolio et al. 2017) \\
\hline PBL: MJY (Mellor and Yamada 1982) & Cumulus: Kain-Fritsch (Kain 2004), only BOLAM \\
\hline \multicolumn{2}{|c|}{ Surface layer: Eta similarity (Janjić 1994) } \\
\hline \multicolumn{2}{|c|}{ Land surface model: Unified NOAH (Tewari et al. 2004) } \\
\hline \multicolumn{2}{|c|}{$\begin{array}{l}\text { SST boundary conditions: sst_update, allowing dynamical SST, } \\
\text { and sst_skin (Zeng and Beljaars 2005), accounting for SST } \\
\text { dynamics }\end{array}$} \\
\hline \multicolumn{2}{|c|}{ IC and BCs: ERA-Interim/ERA5 } \\
\hline \multicolumn{2}{|c|}{ ERA-Interim: resolution $0.755^{\circ} \times 0.755^{\circ}$, pressure level data, every $6 \mathrm{~h}$} \\
\hline \multicolumn{2}{|c|}{ ERA5: resolution $0.25^{\circ} \times 0.25^{\circ}$, pressure level data, every $3 \mathrm{~h}$} \\
\hline \multicolumn{2}{|c|}{ SST: native ERA-Interim/ERA5 SST fields; Medspiration Project, resolution $2.2 \mathrm{~km}$, updated every $24 \mathrm{~h}$} \\
\hline
\end{tabular}

Given the impulsive features of the events that develop in a short time, the baseflow model is switched off. Initial soil moisture conditions are very important for defining the hydrological response of the catchments. However, land surface related processes need a considerably longer adjustment period than those of the atmosphere (e.g., Hong and Kanamitsu 2014). Therefore, in the two autumn case studies (November 2015 and November 2016 in Table 2) the soil moisture and temperature ICs are determined using offline simulations with a spinup time of 1 month. Instead, since the summer event occurred after almost two hot and dry months, leading to homogeneously dry conditions, soil moisture and temperature ICs are taken from the coarser ERA-Interim reanalysis. River runoff ICs are assumed consistently to observations, where available. WRF-Hydro is selected for this study because, besides being particularly suitable for the atmospheric-hydrological model coupling, it was already calibrated for the Ancinale River and Bonamico Creek catchments, also coping with the problem of missing discharge data. As explained in detail by Senatore et al. (2020), the model calibration was performed manually with respect to the available water level data for the events of 2015, reproducing the timing of the hydrological response to heavy precipitation and the peak flow time. Therefore, in this study simulated discharges and hydrographs are compared with those calculated by the calibrated WRF-Hydro model driven by observations (i.e., using the merged rain gauge-radar rainfall fields).

\section{d. Performance indices}

As it will be described in section 3, while the summer 2015 event was localized and seriously hit only a small portion of the area of interest, the two autumn events affected almost the whole region, and hence, for the latter two, the performance evaluation can exploit all the rain gauges of the monitoring network. The evaluation strategy uses traditional scores based on a typical $2 \times 2$ contingency table. Three simple scalar attributes of the contingency table are selected (Wilks 2006), namely, the frequency bias index (FBI), the probability of detection (POD), and the false alarm rate (FAR):

$$
\begin{aligned}
\mathrm{FBI} & =\frac{\text { hits }+ \text { false alarms }}{\text { hits }+ \text { misses }}, \\
\mathrm{POD} & =\frac{\text { hits }}{\text { hits }+ \text { misses }}, \\
\mathrm{FAR} & =\frac{\text { false alarms }}{\text { hits }+ \text { false alarms }} .
\end{aligned}
$$

TABLE 2. Starting time and range of the high-resolution WRF and MOLOCH simulations.

\begin{tabular}{llc}
\hline \hline \multicolumn{1}{c}{ Case study } & Initialization time & Range (h) \\
\hline August 2015 & 0000 UTC 11 Aug & 48 \\
November 2015 & 0000 UTC 30 Oct & 96 \\
November 2016 & 0000 UTC 24 Nov & 60 \\
\hline
\end{tabular}


Specifically, FBI measures the ratio of the frequency of forecast events to the frequency of observed events. A value of FBI smaller (larger) than 1 is associated with a NWP system that has a tendency to underforecast (overforecast) events. Therefore, FBI $=1$ for a perfect prediction. However, FBI only measures relative frequencies and not the correspondence between forecasts and observations. A more elaborate skill score, the equitable threat score (ETS), is also used:

$$
\text { ETS }=\frac{\text { hits }- \text { hits }_{r}}{\text { hits }+ \text { misses }+ \text { false alarms }+ \text { hits }_{r}},
$$

where

$$
\text { hits }_{r}=\frac{(\text { hits }+ \text { misses })(\text { hits }+ \text { false alarms })}{\text { hits }+ \text { misses }+ \text { false alarms }+ \text { correct negatives }} .
$$

ETS measures the fraction of observed and/or forecast events that were correctly predicted, adjusting for hits associated with random chance (hits ${ }_{r}$ ). It is considered suitable for NWP verification because it allows scores to be compared more fairly across different regimes. Its value ranges between $-1 / 3$ and 1 , being 1 for a perfect forecast; 0 indicates no skill.

All the scores are calculated considering consecutive 6-h accumulated rainfall for the periods of interest, using the following precipitation thresholds $t_{h}$ :

$$
\left\{\begin{array}{lcl}
0.2 \mathrm{~mm} \leq \text { rainfall } \leq 1 \mathrm{~mm} & t_{h}=0.2 \mathrm{~mm} \times i & \text { with } i=1, \ldots, 5 \\
1 \mathrm{~mm}<\text { rainfall } \leq 10 \mathrm{~mm} & t_{h}=1 \mathrm{~mm} \times i & \text { with } i=1, \ldots, 10 \\
10 \mathrm{~mm}<\text { rainfall } \leq 20 \mathrm{~mm} & t_{h}=2 \mathrm{~mm} \times i & \text { with } i=1, \ldots, 5 \\
20 \mathrm{~mm}<\text { rainfall } & t_{h}=5 \mathrm{~mm} \times i & \text { with } i \text { integer }
\end{array}\right.
$$

The comparison between observations and models is performed extracting from the latter the value from the closest neighboring cell.

An additional performance index, the fractions skill score (FSS; Roberts and Lean 2008; Roberts 2008) is also applied. Assuming a square-shaped neighborhood of length $n, \mathrm{FSS}_{n}$ is given by

$$
\mathrm{FSS}_{n}=1-\frac{\frac{1}{N} \sum_{i} \sum_{j}\left[F_{o}(i, j)-F_{m}(i, j)\right]^{2}}{\frac{1}{N} \sum_{i} \sum_{j} F_{o}(i, j)^{2}+\frac{1}{N} \sum_{i} \sum_{j} F_{m}(i, j)^{2}}
$$

where $N$ is the number of all grid points in the domain, while $F_{o}(i, j)$ and $F_{m}(i, j)$ are the observation and forecast fractions (calculated with respect to a specific rainfall threshold) at the location $(i, j)$. Evaluating fractional coverage over different sized areas, FSS is a spatial verification measure used to assess precipitation forecasts performance. FSS measures how the skill of precipitation forecasts varies with spatial scale (Roberts and Lean 2008) and indicates the spatial scales at which the forecast resembles the observations. It was developed to overcome some limitations of gridpoint-by-gridpoint verification methods especially for high-resolution models. In this study, FSS is applied to the total accumulated precipitation of the two autumn events using a rainfall threshold equal to the 90th percentile. The use of a percentile rather than a fixed accumulated threshold removes the impact of the bias in rainfall amount on the FSS, thus focusing on the spatial accuracy of the model simulation.
This information is complementary to that provided by the other skill scores presented above.

Since rainfall observations are accurate only over land, where rain gauges and radar data are merged, the FSS computation domain does not correspond to a square or rectangular domain, but is limited by the Calabria region borders. Problems in FSS calculation close to the region boundaries can arise, as discussed in Skok and Roberts (2016), especially due to the complex shape of the region and the small size of the computational domain. The approach used here is the one proposed by Roberts and Lean (2008), who assign a value of zero precipitation to points outside the domain.

\section{Heavy precipitation and flood events}

Three heavy precipitation events associated with recent floods have been selected. They occurred in different seasons and presented different characteristics in terms of precipitation type (orographic, convective, and stratiform), duration and location. Thus, they represent a suitable, although small, ensemble of heavy precipitation events that typically affect the region. A general description of the events is provided in the following, using reanalysis products to describe the main synoptic patterns.

\section{a. 11-12 August 2015 event}

During 9 August, an upper-level cold cyclone isolated from the main Atlantic cyclonic circulation and moved across southern France, reaching the Mediterranean 
basin the day after. Moving southeastward, the cutoff low crossed Sardinia and by 0000 UTC 12 August was located over Sicily. The instability associated with cold air advection in the middle troposphere produced widespread severe convective weather over southern Italy.

The cyclonic circulation in the lower levels produced southerly winds on 11 August (Figs. 3b,c), progressively turning to southeasterly, as a consequence of the southward displacement of the low, on 12 August, when the convective activity attained its maximum intensity. Convective cells developing over the Ionian Sea were advected toward the coast of Calabria, affecting mainly the northern part of the region (Figs. 3a, showing merged rain gauge and radar precipitation data, and Figs. 3d,e). Heavy rainfall was localized, reaching $255 \mathrm{~mm}$ in $24 \mathrm{~h}$ (233 mm in just $12 \mathrm{~h}$; CFM 2015a) at the Corigliano Calabro rain gauge (Fig. 1a). Only a few very small catchments were hit by the event, including Citrea Creek, where flood and damages were recorded.

\section{b. 31 October-2 November 2015 event}

As a consequence of typical Alpine cyclogenesis, a cutoff low isolated over Sicily during the last days of October. A strong high pressure ridge progressively developing over western Europe, up to the Scandinavian Peninsula, produced temporary blocking in the westerly synoptic currents over the Mediterranean. By 1 November, the synoptic pressure pattern was characterized by a dipole, with a high pressure center over central-eastern Europe, and a cold-core low pressure system almost stationary between Tunisia and Sicily. The cyclonic circulation around the surface low over the Ionian Sea (Figs. 3g,h) conveyed southeasterly moist flow from the eastern Mediterranean in the lower troposphere, and from northern Africa slightly above, toward Calabria. Increasing wind intensity and moist air impinging the southern Apennines produced heavy precipitation (Figs. 3i,j) for several days, from the evening of 30 October to the early morning of 2 November, when the cutoff low finally dissipated.

Heavy rainfall affected the southern portion of the Calabria region, mainly on its Ionian side (Fig. 3f, merged rain gauge and radar precipitation data). On 30 October precipitation exceeding $100 \mathrm{~mm}$ was confined to the north of the region, but moved to the south following the cyclone movement, becoming progressively more intense during 31 October and 1 November. Rainfall exceeding $200 \mathrm{~mm}$ in $24 \mathrm{~h}$ was recorded in several gauges during both days, producing catastrophic flooding. In particular, a rain gauge located in Sant'Agata del Bianco (Fig. 1a) measured almost $400 \mathrm{~mm}$ in $24 \mathrm{~h}$, while one at Chiaravalle Centrale (Fig. 1a) recorded maximum rainfall amount of $739 \mathrm{~mm}$. Although the effect of orographic forcing is evident in the precipitation field, the convective activity was also intense, as demonstrated by a large amount of lightning (not shown), especially over the Ionian Sea and along the Calabrian coast.

In several basins, repeated discharge peaks were recorded, as a consequence of a long-lasting and persistent precipitation event. Almost $70 \%$ of the region's nearly 400 municipalities were alerted by the regional civil protection agency; 162 experienced the maximum (red) alert level (CFM 2015b). Widespread floods and rain-induced landslides caused severe damage, especially to roads and river banks. The Regional Civil Protection Agency estimated damage worth almost 60 million euros.

\section{c. 25-26 November 2016 event}

This event affected mainly the Ionian side, particularly its southernmost tip. The frontal system, associated with depression "Queenie" centered over Spain, crossed southern Italy during the night between 25 and 26 November. Several factors contributed to a strongly unstable troposphere and thus to particularly intense convective activity, as evidenced by the large number of lightning (not shown): the presence of a strong subtropical jet stream; intense low-level advection of warm, moist air from the south, which produced very high values of equivalent potential temperature (e.g., exceeding $320 \mathrm{~K}$ at $850 \mathrm{hPa}$ ) in the prefrontal area; and high CAPE values, denoting potential for strong convection over the Ionian Sea. The strong large-scale forcing with prevailing southeasterly flow at the surface (Figs. 31,m), impinging on the Apennines, southwesterly currents in the middle troposphere, and frontal passage, drove convection mainly over the southernmost tip of Calabria and the eastern part of Sicily, where most of the precipitation occurred (Figs. 3k,n,o). It was concentrated in two different phases: a prefrontal period, on the morning of 25 November, and a frontal phase that night. In $24 \mathrm{~h}, 400 \mathrm{~mm}$ fell at the rain gauge of Sant'Agata del Bianco, but values exceeding $200 \mathrm{~mm}$ were recorded over a larger area, where precipitation started on the morning of 25 November. Peaks of almost $100 \mathrm{~mm}$ in $1 \mathrm{~h}$ and $150 \mathrm{~mm}$ in $3 \mathrm{~h}$ are consistent with the presence of intense deep convection. Some small basins reacted quite quickly to the intense precipitation with remarkable discharge peaks in the early morning of both 25 and 26 November. According to the alert issued by the regional civil protection agency, about $30 \%$ of the region's municipalities were affected by the hydrological impact of the event ( 55 of them received the maximum alert level; CFM 2016). Damages similar to the 2015 autumn 
a)

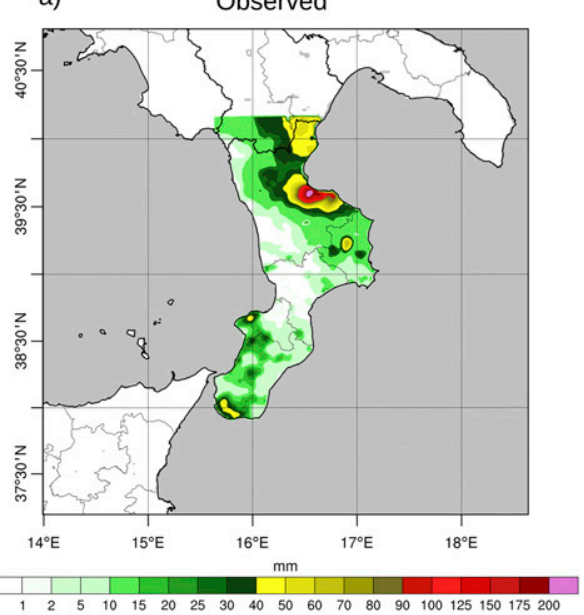

b)
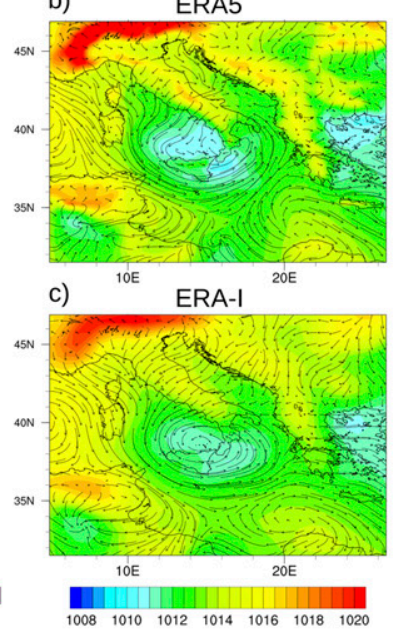

g)

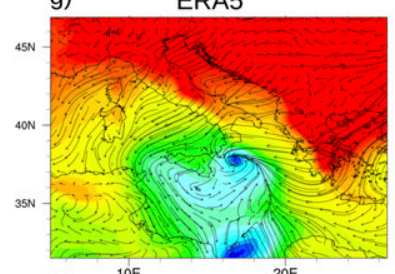

h)

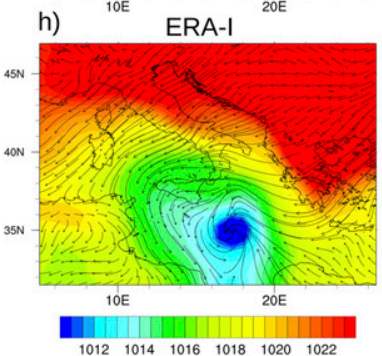

$1012 \quad 1014 \quad 1016 \quad 1018 \quad 1020 \quad 1022$

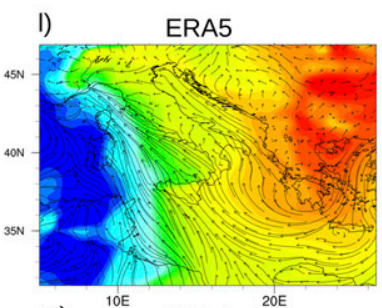

m)

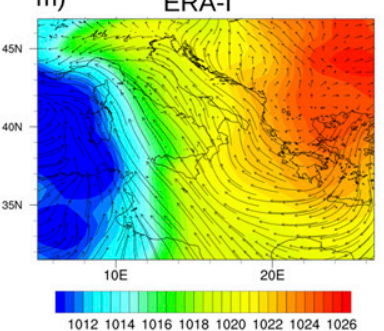

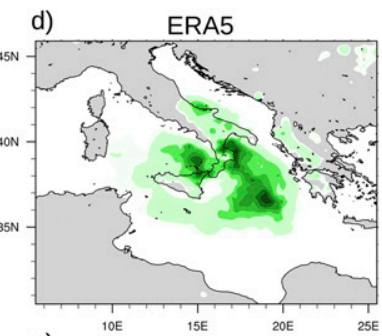

e)
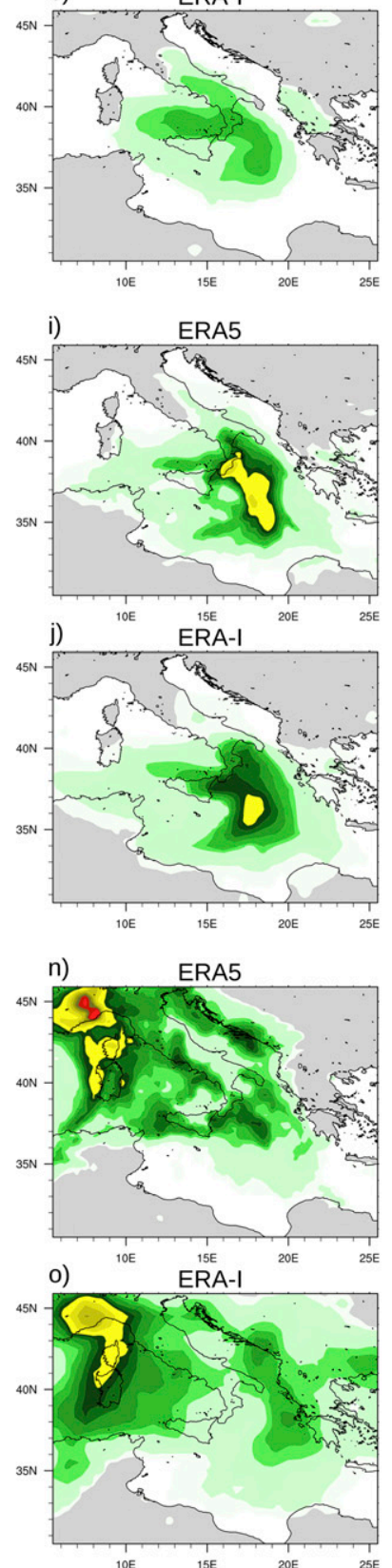

FIG. 3. (left) Observed rainfall interpolated from rain gauge regional network and radar estimates, according to the method proposed by Sinclair and Pegram (2005), (center) surface pressure and 10-m wind, and (right) reanalyzed rainfall from ERA5 and ERA-Interim reanalysis, for the three heavy precipitation case studies: (a)-(e) case study I, (f)-(j) case study II, (k)-(o) case study III. Shown in (a), (d), and (e) is 24-h rainfall at 1800 UTC 12 Aug 2015, and in (b) and (c) valid at 0000 UTC 12 Aug 2015. Shown in (f), (i), and (j) is 96-h rainfall at 0000 UTC 3 Nov 2015, and in (g) and (h) valid at 0000 UTC 31 Oct 2015. Shown in (k), (n), and (o) is 54-h accumulated rainfall at 0600 UTC 26 Nov 2016, and in (l) and (m) valid at 1200 UTC 24 Nov 2016. 
event occurred. The Regional Civil Protection Agency, evaluating this event together with a subsequent one that occurred in January 2017, estimated damage worth about 75 million euros.

\section{Simulation results: Meteorological perspective}

\section{a. Differences between the reanalysis products and SST representations}

The two modeling chains are driven by ERA-Interim and ERA5 reanalyses. Before analyzing the details of the high-resolution simulations of WRF and MOLOCH, it is worth to discussing differences between the global forcing fields. Although the synoptic pressure pattern in the middle troposphere over the Mediterranean is only slightly different (e.g., geopotential at $500 \mathrm{hPa}$, not shown), remarkable differences appear in the surface pressure field. For the November 2015 event in particular (Figs. 3g,h), the cyclonic circulation over the Ionian Sea is farther north in ERA5 than in ERA-Interim, with greater intensity and stronger gradients around the center, producing stronger winds and sharper convergence. In August, the surface cyclone over Sicily also presents a different shape and location, partially ascribable to the different orography of the two reanalyses. The impact of the higher resolution in ERA5 is especially evident in the dynamical fields of the lower troposphere. In particular, the wind field at $10 \mathrm{~m}$ highlights a stronger orographic effect across the Mediterranean, where the flow is much more perturbed on the lee side of the mountains with respect to ERA-Interim. Both the Apennines and the Alps exert a stronger blocking effect on the low-level flow (see, e.g., Figs. 3b,c), but also around Sardinia, Corsica, and Sicily (Figs. 31,m) the impact of the better-resolved orography is clear. Beyond orographic effects, ERA5 displays sharper convergence lines (Figs. 3g,h,l,m), which may initiate convection over the sea. It is also worth noticing that ERA5 reproduces areas of low-level convergence and vertical motion possibly associated with explicit convection over the Tyrrhenian Sea.

Rainfall in ERA5 is systematically more intense than in ERA-Interim, but both reanalyses markedly underestimate the observed precipitation across southern Italy (Fig. 3). In particular, ERA-Interim hardly reproduces heavy orographic precipitation over the Calabria region, where only light rain is shown. Underestimation by the ERA5-driven simulations is particularly evident for the last event (Figs. 3n,o), while providing heavy rain for the other two.

Finally, concerning the SST representation, both ERA-Interim and ERA5 rely on the Operational Sea
Surface Temperature and Sea Ice Analysis (OSTIA) product (Stark et al. 2007). Therefore, the mean SST values are very similar. Focusing on the innermost domains of both mesoscale models, average SST values for the ERA5 and ERA-Interim fields providing initial conditions are within $0.1^{\circ} \mathrm{C}$ for all the three analyzed events. On the contrary, the Medspiration SST product shows some noteworthy variations. Specifically, in the innermost domains, the mean SST of Medspiration fields is almost systematically warmer by about $0.4^{\circ} \mathrm{C}$ in the summer 2015 event and $1.3^{\circ} \mathrm{C}$ in the autumn 2015 event, while for the autumn 2016 event it is very close to the reanalyses (average differences $<0.1^{\circ} \mathrm{C}$ ).

\section{b. Case study I (11-12 August 2015)}

For all case studies, precipitation fields from eight high-resolution simulations are available (Fig. 4), combining the two different convection-permitting models (WRF and MOLOCH), ICs and BCs (ERA-Interim and ERA5) and SST initialization fields (native from reanalyses and Medspiration dataset), as described in sections $2 b$ and $2 c$. The main aim of the comparison among these precipitation fields is to identify difference that recurs in both mesoscale model simulations, in order to disentangle the effects ascribable to the different reanalyses or to different SST initialization. Moreover, in order to assess the impact of the reanalyses for the reconstruction of extreme meteorological events, a qualitative and quantitative evaluation of the dynamical downscaling (via WRF and MOLOCH) of the reanalyses is provided, comparing model results (Fig. 4) against observations (Fig. 3).

The first eight panels (Figs. 4a-h) show the results for the August 2015 convective event. The maps of 24-h accumulated precipitation from 1800 UTC 11 August to 1800 UTC 12 August 2015 highlight the scattered and chaotic nature of rainfall due to widespread convective activity across the Ionian Sea and Calabria region. Almost all simulations successfully reproduce small rainfall clusters with high intensity (exceeding $100 \mathrm{~mm}$ in $24 \mathrm{~h}$ ), even though their location over land does not always correspond to the exact location where heavy localized precipitation is observed. For both WRF and MOLOCH, the highest amount of accumulated precipitation averaged across the domain is obtained with the simulations driven by ERA5 with native SST fields (Figs. 4b,f).

The slightly warmer Medspiration SST field, which may potentially increase the low-level instability and moisture content, generally has a negligible (ERA-Interim-driven simulations) effect or may even produce a slight decrease in precipitation amount (ERA5-driven simulations). In general, MOLOCH seems to be less sensitive to the SST 


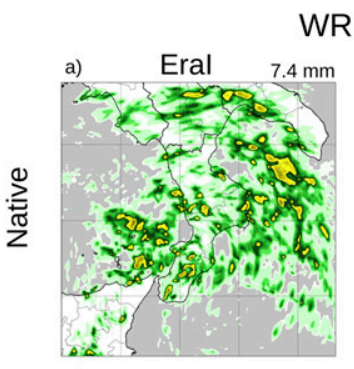

RRF
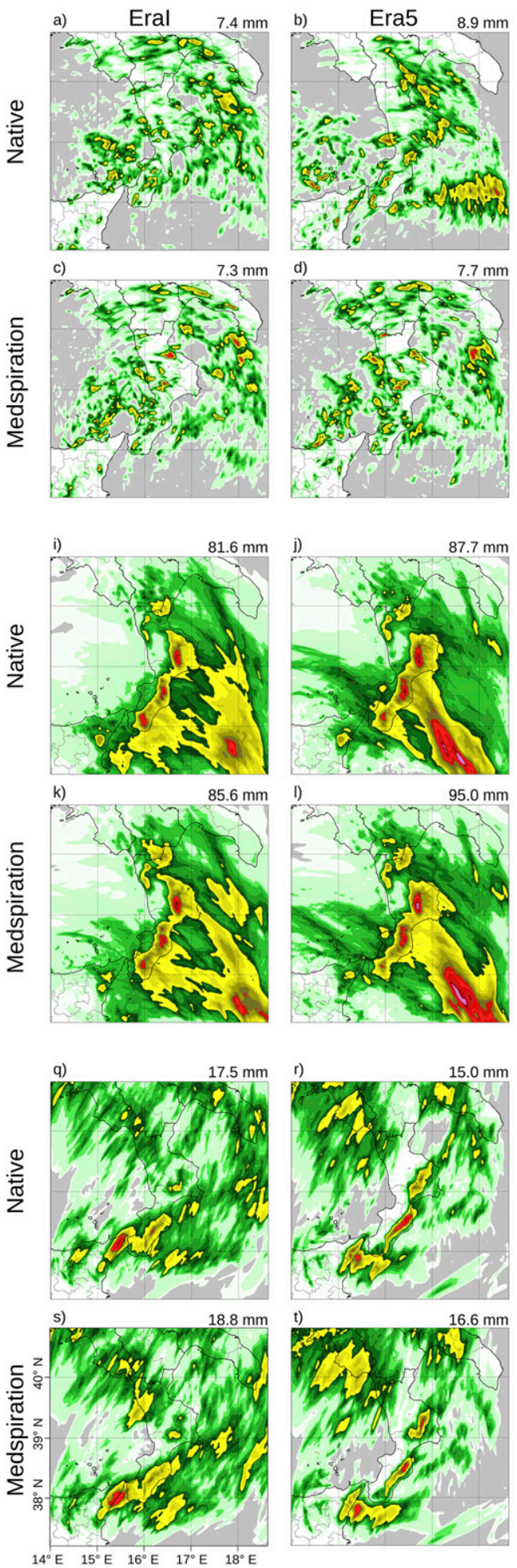

$\mathrm{MOLOCH}$

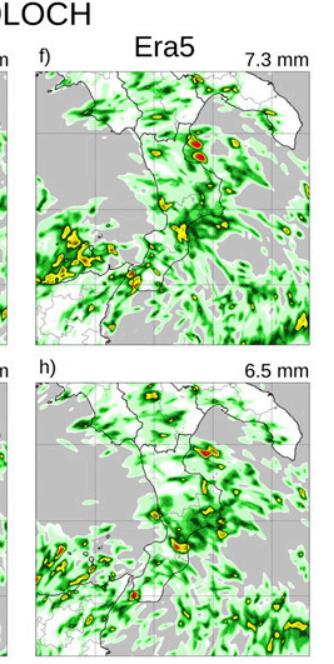

Case
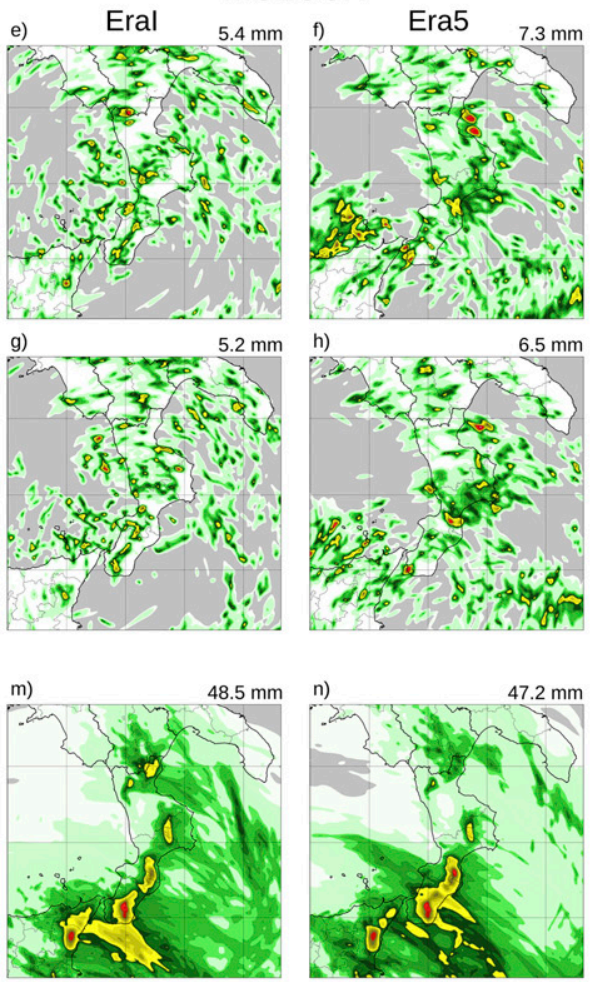

Case

Study

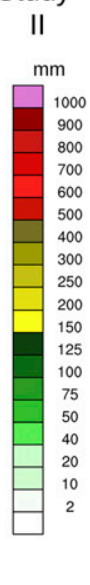

Case
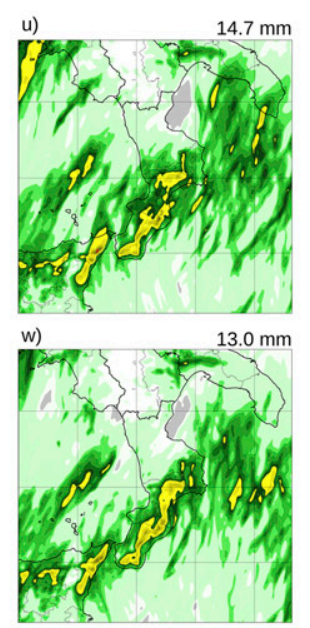

Study
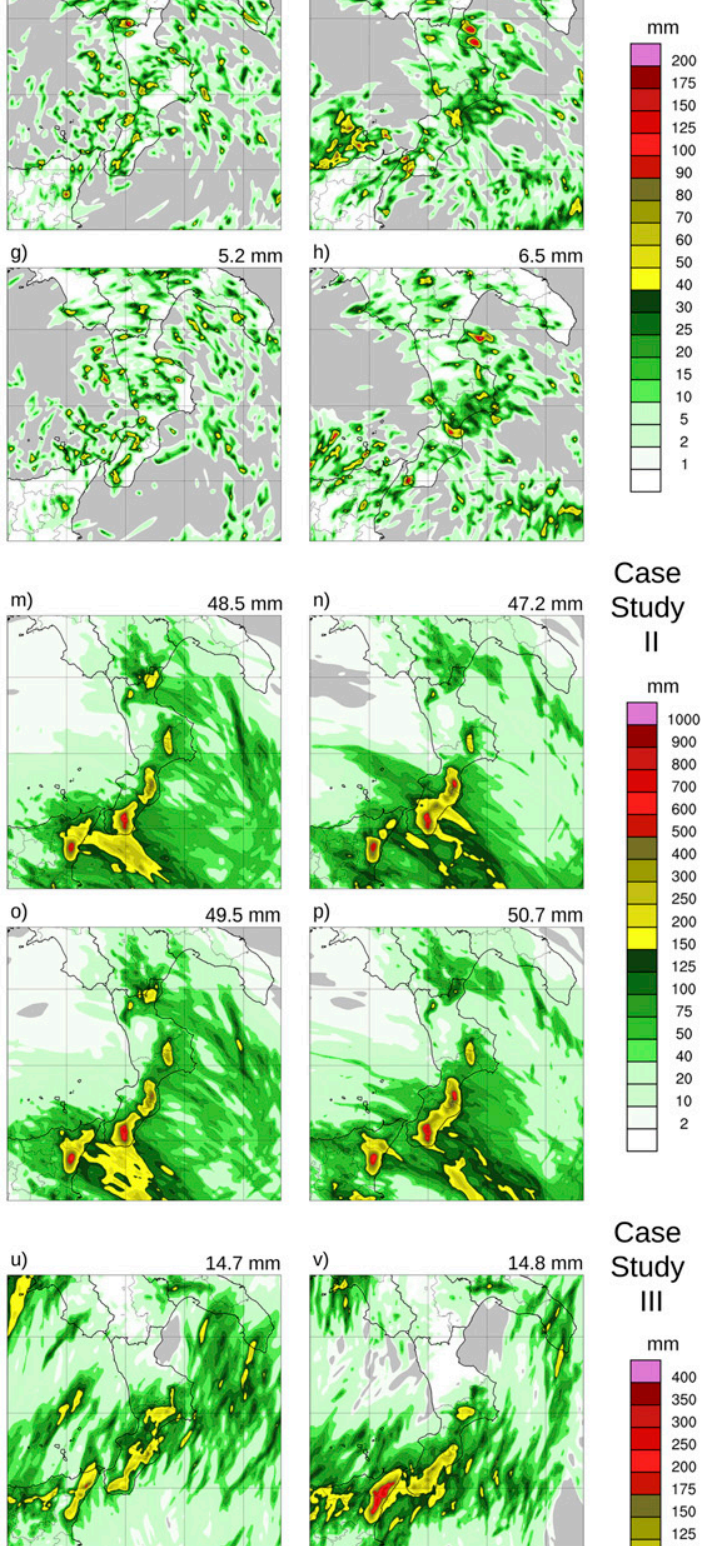

Study

FIG. 4. Simulated accumulated precipitation for the three case studies. (a)-(h) 24-h rainfall at 1800 UTC 12 Aug 2015; (i)-(p) 96-h rainfall at 0000 UTC 3 Nov 2015; (q)-(x) 54-h rainfall at 0600 UTC 26 Nov 2016. Numerical experiments with WRF (left two columns) and MOLOCH (right two columns) driven by ERA-Interim and ERA5 (as indicated at the top of each column) and different SST (as indicated on the left of each row), as described in Table 1. Simulated precipitation can be directly compared with observations shown in Fig. 3. Numbers on the top right of each panel indicate the average precipitation over the area. 


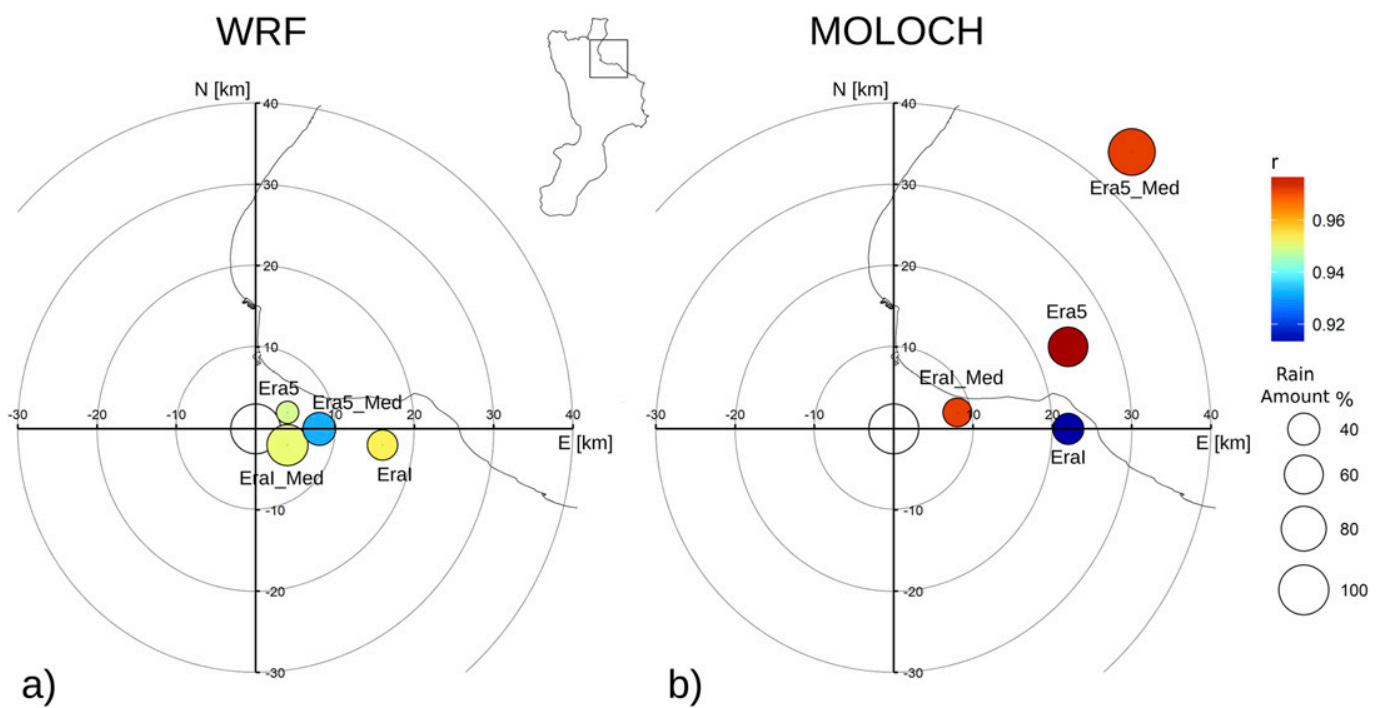

FIG. 5. Case study I: rainfall peaks in a 50-km neighborhood around the Corigliano Calabro rain gauge. (a) WRF and (b) MOLOCH simulations. The origin of the axes corresponds to the rain gauge location. For each simulation, the circle highlights the rainfall peak location, its color refers to the time correlation (Pearson correlation coefficient $r$ ), and the size to the percentage rain amount with respect to observations.

initialization and the two simulations driven by the same reanalysis closely resemble one another. Relatively larger differences are produced in WRF simulations, especially over the sea. This behavior may be due to the different SST evolution prescribed in the two models (the "sst_skin" model with WRF and a simple slab ocean model with MOLOCH; Stocchi and Davolio 2017).

To address the question of whether the high-resolution simulations driven by different reanalyses (ERA5 vs ERA-Interim) are capable to reproduce better the observed precipitation, the analysis focused on an area where very localized, heavy rainfall produced its major impact, i.e., around the Corigliano Calabro rain gauge. Figure 5 shows, for both WRF and MOLOCH simulations, the location and the relative amount (compared to observations) of the highest rainfall peaks within 50 of that station, together with the time correlation of simulated and observed accumulated hourly precipitation. The choice of a 50-km neighborhood addresses the challenge of very low predictability typical of a scattered convective event. Whether location, intensity, or temporal correlation are considered, there are no clear indications about the best performing configuration, while all the simulations underestimate the event. In more detail, MOLOCH driven by ERA5 produces a rainfall peak whose intensity is very close to that observed, but located about $40 \mathrm{~km}$ away; among WRF simulations, those using the Medspiration SST field predict more intense peaks, while the location differences are very small. Time correlations are always quite high for both models, ranging from 0.92 to 0.98 .
Summarizing, the reconstruction of the convective event through convection-permitting, high-resolution dynamical downscaling does not clearly benefit from the potentially improved ICs and BCs provided by the ERA5 reanalysis and the Medspiration SST product. Several modeling and data uncertainties in the mesoscale simulations, as well as the unpredictable nature of the convection, probably prevail and hide the potential offered by these more accurate datasets.

\section{c. Case study II (31 October-2 November 2015)}

This event is characterized by persistent precipitation, lasting for almost 4 days, which affects the southern side of the Calabria Apennines. This pattern is correctly simulated by both models, as shown in Figs. 4i-p, although simulations differ over the Ionian Sea, a probable consequence of the different size of WRF and MOLOCH integration domains.

The rainfall distribution appears very sensitive to the driving reanalyses, particularly over the sea, while the precipitation pattern and even the intensity over the orography are more similar. A marked increase in the precipitation amount is observed in WRF when ERA5 is used. In MOLOCH the use of ERA5 in place of ERAInterim slightly changes the rainfall pattern over the sea and increases the intensity of the precipitation peaks over the orography. On the other hand, a warmer SST provided by Medspiration analysis (about $+1.3^{\circ} \mathrm{C}$, averagely) only modestly increases average accumulated precipitation in the innermost domain for both models, although more evident with WRF (consistent with the 
results of Senatore et al. 2020), but the impact is considerably lower than that observed by changing the BCs. Analyzing the precipitation timing more closely shows that different SST fields have negligible effect, probably because strong large-scale forcing and the wide spatial and long time scales of the event mask possible effects of PBL dynamics due to SST.

The quantitative evaluation of the simulation accuracy is first performed directly against 140 rain gauges of the regional network (i.e., radar data are not considered) computing the gridpoint-based statistical indexes presented in section $2 \mathrm{~d}$.

In agreement with the analysis carried out so far across the entire innermost domain, the FBI plots (Figs. 6a,b) confirm an increase of rainfall amount over land for both WRF and MOLOCH models when ERA5 BCs are used, for almost every threshold. Moreover, while WRF shows a slight tendency toward overforecasting (FBI slightly larger than 1), MOLOCH underforecasts rainfall especially for high thresholds (FBI reaching 0.5 ). On the other hand, the effect of the Medspiration SST fields is not so evident, suggesting that the accumulated precipitation in the domain increases more over the sea surface than over land, where the scores are computed. ETS generally indicates a worsening of both mesoscale models when ERA5 BCs are applied, for higher thresholds $(>5 \mathrm{~mm})$ (Figs. 6c,d). POD results (Figs. 6e,f) are less peremptory and highlight a comparable probability of detection using different BCs. Results achieved by FBI, ETS, and POD are further confirmed by the FAR score (Figs. 6h,i): the probability of false alarms is lower with ERA-Interim BCs, as expected with lower values of the FBI score.

The capability of the simulations to reproduce the spatial distribution of precipitation across Calabria is assessed through the FSS. Figure 7 shows FSS values for all simulations and for different neighborhood lengths. As indicated in Roberts and Lean (2008), two horizontal lines are drawn in a FSS graph. The lower dotted line represents the FSS value that would be obtained by a random forecast with the same fractional coverage of the observed field. The upper dotted line is the FSS target value; the value of $\mathrm{n}$ corresponding to the point where the FSS curve crosses this line, indicates the smallest scale over which the forecast output contains useful information.

The 90th percentile is selected in order to evaluate the spatial accuracy of model simulations with respect to heavy precipitation. Results show an opposite behavior of the two mesoscale models: while WRF performs better when ERA-Interim BCs are used, MOLOCH is more accurate when ERA-5 reanalyses are adopted. FSS confirms that simulations are more sensible to the
BCs than to the SST analysis, but in any case, the use of high-resolution SST does not improve the accuracy of the simulated precipitation. The complementarity of the adopted skill scores (discussed in section 2d) affirms that MOLOCH accurately simulates the location of intense precipitation (FSS), but with a relevant underestimation of the peaks (FBI and ETS), while WRF is less accurate in terms of positioning but much closer to the observed maximum intensity.

As for the first case, the use of potentially improved BCs of ERA5 (higher resolution, better model, and data assimilation) similarly does not improve the simulations. For this event, the variability brought by the adopted mesoscale model is considerable and exceeds the influence of initial/boundary conditions. The analyzed maps clearly show that only where the precipitation is constrained by the orographically forced uplift, do the two models provide similar results. Elsewhere, large differences over the sea are associated with intense and persistent convection, much more active than for the other events. Therefore, differences in dynamics and microphysics, as well as in domain set up, may rapidly grow where convective instability dominates.

\section{d. Case study III (25-26 November 2016)}

The accumulated precipitation maps in the innermost domain are shown in Figs. 4q-x and depict a 54-h period from 0000 UTC 24 November to 0600 UTC 26 November 2016. Rainfall amounts differ sharply between the two mesoscale models. With WRF, ERAInterim BCs lead to more area-averaged rain than ERA5 BCs, especially over the southern tip of Calabria and eastern Sicily. Moreover, when driven by ERA5, WRF seems excessively dry on the lee side of the southern Apennines. With MOLOCH, averaged values are similar among the two sets of experiments, but rain peaks are much more intense over southern Italy using ERA5 as BCs. Despite the very small average difference between the SST fields used in the initialization (as stressed in section 4a) some differences emerge in the experiments using Medspiration data. Both WRF simulations show a slight increase in average precipitation, although the location and intensity of the most intense peaks remain quite close to the reference experiments. By contrast, MOLOCH simulates a slight decrease in area-averaged rainfall, despite similar spatial patterns. This different behavior and this sensitivity may be explained by the fact that the SST is also changed in the parent model domains. That is, the two different downscaling procedures (i.e., WRF and BOLAM/MOLOCH) elaborate such information differently, leading to contrasting precipitation amounts. This different behavior is a clear example of the intrinsic uncertainty in the 

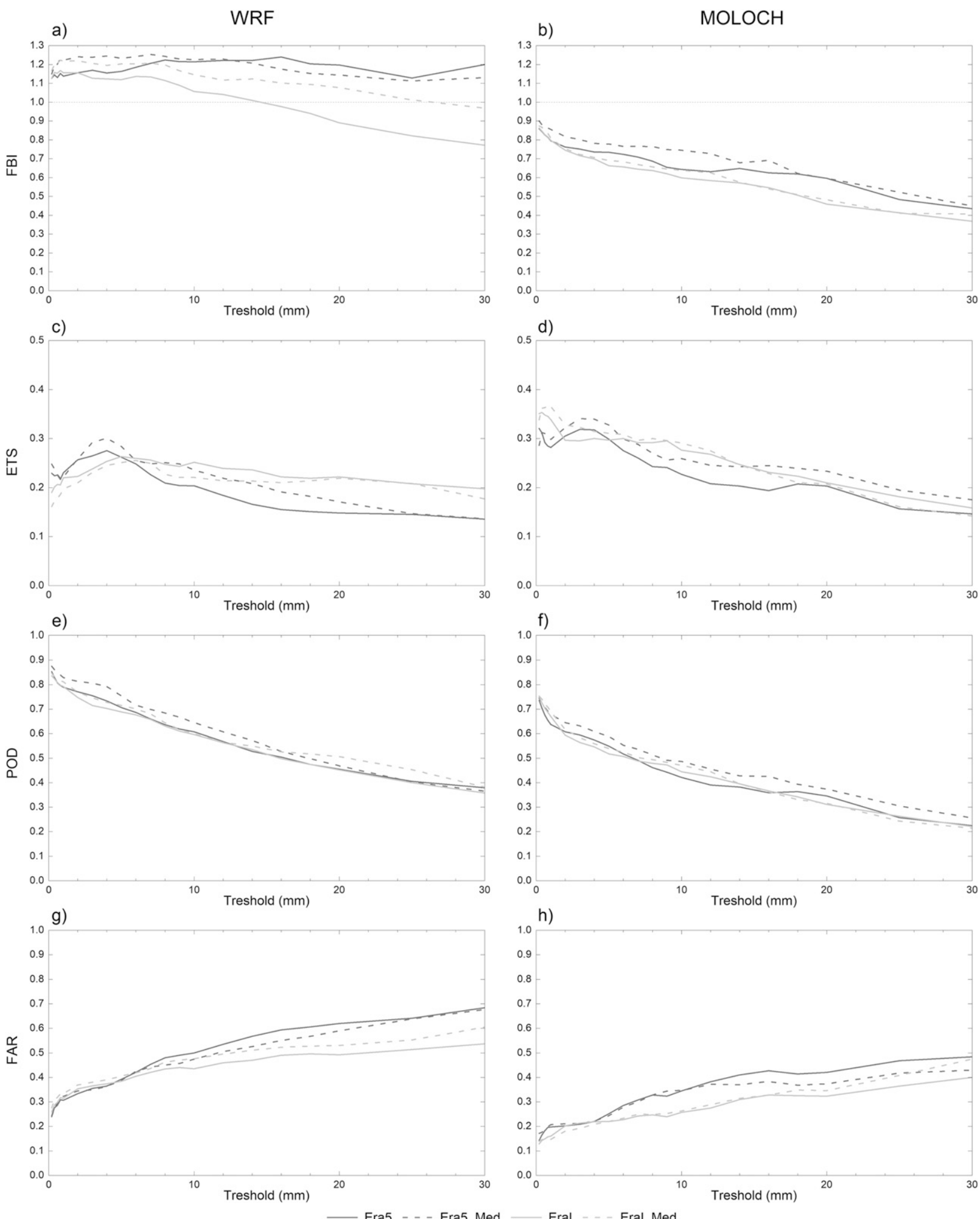

FIG. 6. Scores computed for the different (left) WRF and (right) MOLOCH simulations for case study II (31 Oct-2 Nov 2015). (a),(b) FBI, (c),(d) ETS, (e),(f) POD, and (g),(h) FAR. All scores are calculated considering consecutive 6-h accumulated rainfall for the periods of interest. Calculation details are illustrated in section $2 \mathrm{~d}$. 

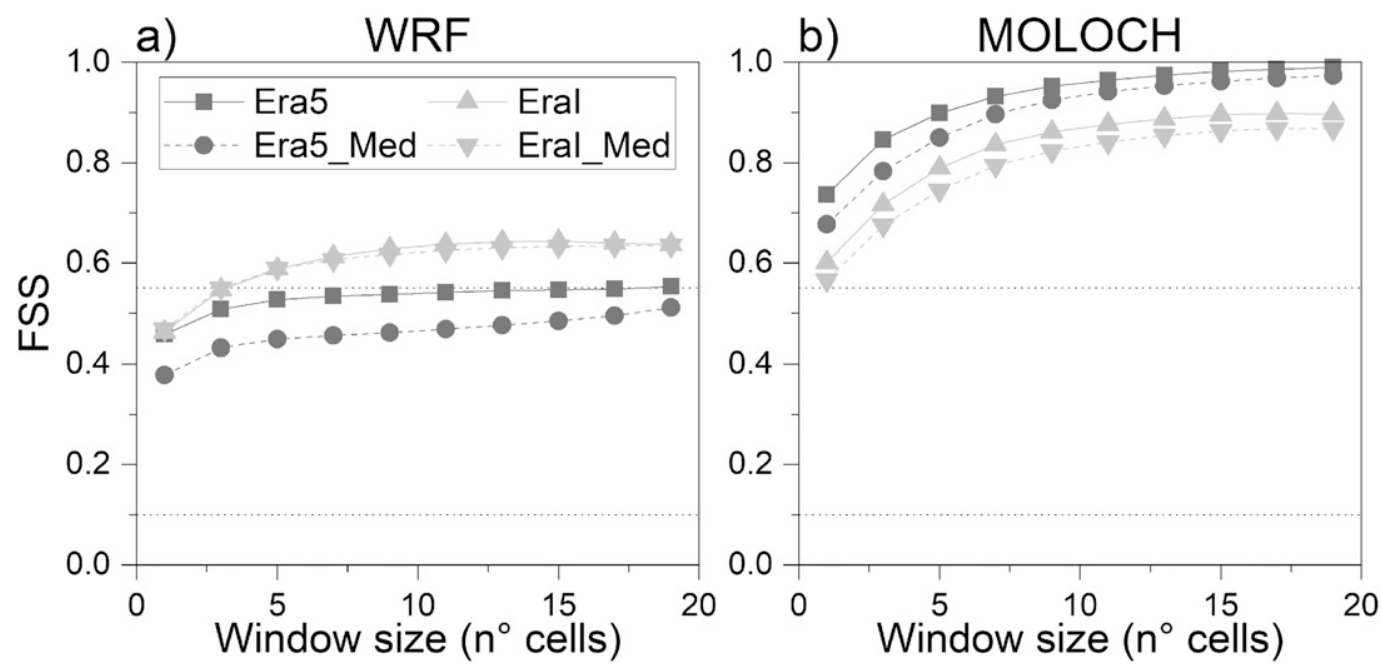

FIG. 7. Case study II: FSS values for (a) WRF and (b) MOLOCH simulations against neighborhood length, using a 90th percentile threshold for total accumulated precipitation. The lowest horizontal dotted line refers to FSS value for a random forecast, and the highest indicates the target value (as explained in section 4c).

downscaling process, overwhelming the uncertainty of the SST input.

The accuracy of the simulations with respect to the observations of the regional monitoring network is evaluated through gridpoint-based skill scores. The FBI (Figs. 8a,b) indicates that both models underforecast the occurrence of rainfall amounts exceeding a specified threshold, within the area where rain gauge observations are available (Calabria region). This behavior is more pronounced in WRF (MOLOCH) for weak (intense) rainfall. The negative bias may be ascribed to the fact that both models not only underestimate the observed rainfall peak in the southern part of the region, but also fail in reproducing a wide area of moderate precipitation $(50-100 \mathrm{~mm}$ in $54 \mathrm{~h}$, Figs. $4 \mathrm{q}-\mathrm{x})$ in the central part of Calabria. For WRF, all the scores in Fig. 8 indicate that a much better performance is attained when ERA-Interim BCs are applied, instead of ERA5. By contrast, with MOLOCH instead, the downscaling of ERA5 and ERA-Interim shows similar performance, with the former (the latter) slightly better for low (high) rainfall thresholds. The use of Medspiration SST fields does not change the overall picture: its effect is generally almost negligible and becomes evident only for higher thresholds where it slightly improves WRF simulations, but worsens those of MOLOCH.

As discussed above, while WRF and MOLOCH both underestimate rainfall, they provide accurate spatial representation of rainfall fields and intense precipitation area, as measured by the FSS (Fig. 9). As in the previous case study, dependency of WRF and MOLOCH on the BCs applied, differs. WRF (MOLOCH) performance is better with ERA-Interim (ERA5). Unlike the previous example, all simulations perform slightly more poorly with the high-resolution SST analysis field.

This case study further confirms the results of the previous one: the influence of the initial/boundary conditions is clearly and highly relevant, regardless the adopted mesoscale model. However, since there is no common behavior between WRF and MOLOCH, it is not possible to draw a general conclusion about the most suitable reanalysis dataset for downscaling of heavy precipitation events, and the different downscaling results seem more ascribable to the mesoscale model. Furthermore, this case study shows that the sensitivity to SST initialization may be very different from case to case and high-resolution products do not necessarily lead to better performance.

\section{Hydrological simulations}

\section{a. Case study I (11-12 August 2015)}

The catchment area of Citrea Creek (the most affected catchment during the convective event of August 2015) covers only about three cells of the innermost domain of the meteorological models. Given the chaotic pattern of the convective precipitation, it is highly unlikely that the modeling chains based on deterministic forecasts can detect such a highly localized impact with sufficient accuracy. Moreover, even if they succeed, a part of randomness should be acknowledged: in fact, none of the rainfall patterns shown in Figs. $4 a-h$ is as wide as that observed in the Corigliano area (Fig. 3a). To cope and deal with such uncertainties, an ensemble approach would be more suitable. 

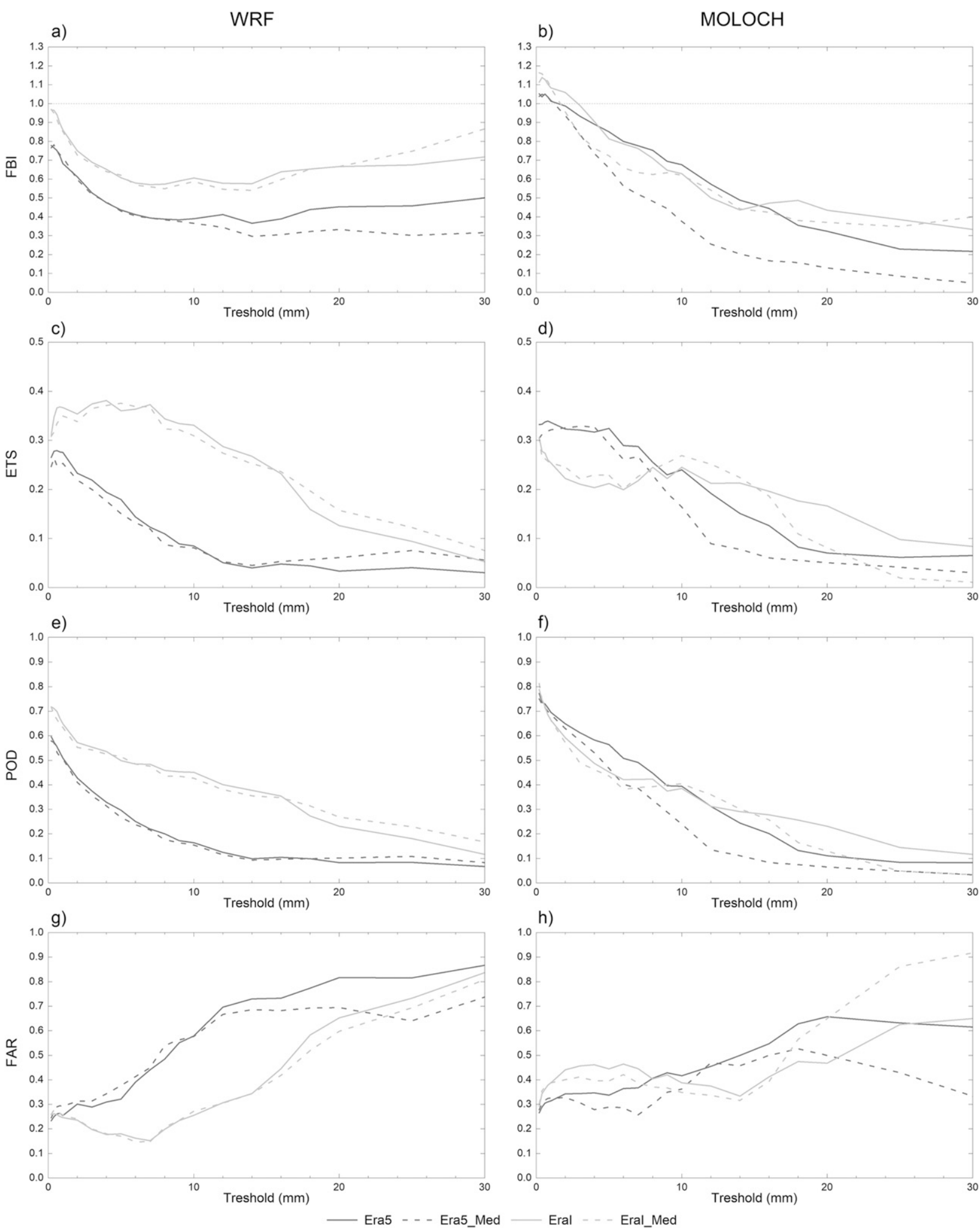

FIG. 8. As in Fig. 6, but for case study III (25-26 Nov 2016). 

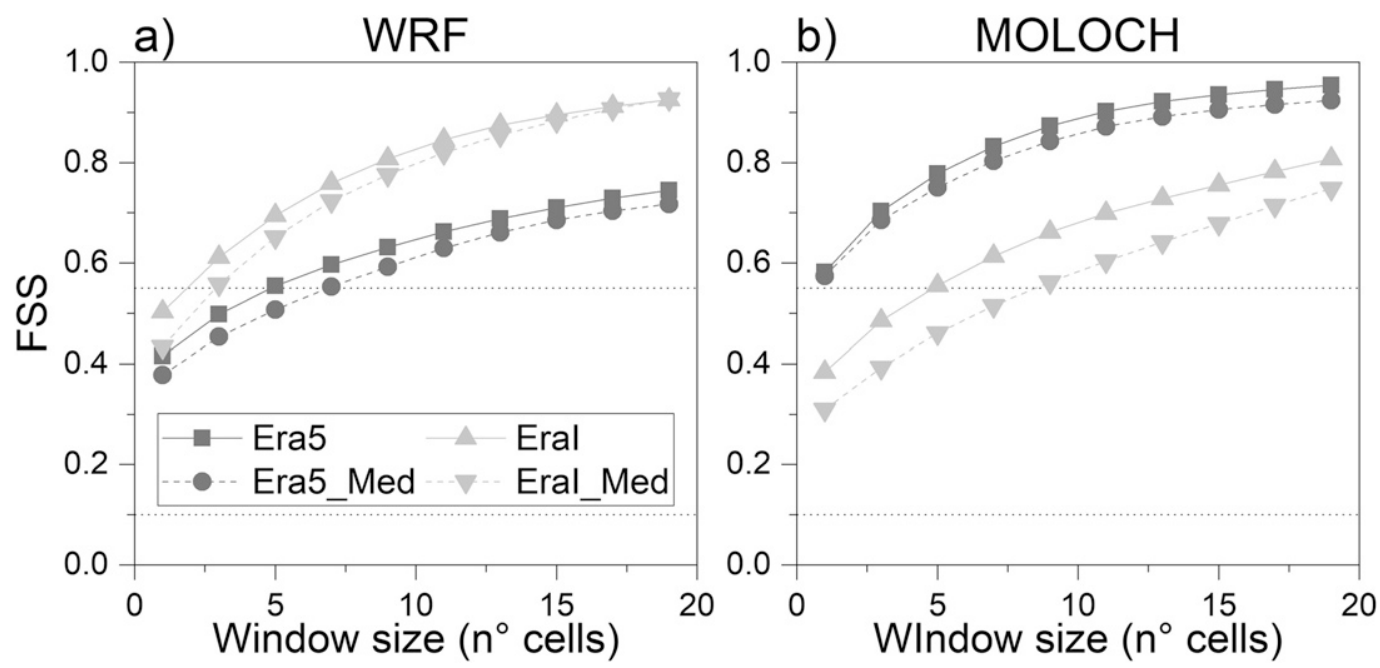

FIG. 9. Case study III: FSS values for (a) WRF and (b) MOLOCH simulations, as in Fig. 7.

Nevertheless, some of the features caught by the mesoscale models' output also produce impacts at the catchment scale. The accumulated precipitation values over the catchment (Table 3) mainly depend on the localization of the rainfall peaks (Fig. 5). Among the MOLOCH simulations, only that driven by ERAInterim with the Medspiration SST field generates nonnegligible amounts of precipitation; however, simulated precipitation is much lower than that recorded at the Corigliano rain gauge, and too low to cause flooding. All WRF simulations, whose rainfall peaks are all located rather close to the catchment area, produce significant accumulated precipitation values, up to almost $80 \mathrm{~mm}$ with ERA5 BCs and Medspiration SST fields. Still, the WRF simulated rainfall is only about $50 \%$ of the amount recorded during the same period (03000800 UTC) by the Corigliano rain gauge (Table 3 ). Nevertheless, it is predicted to occur in only $2 \mathrm{~h}$ (from 0300 to 0500 UTC), entailing a noteworthy peak flow, although earlier than observed (which was at about 0900 UTC; CFM 2015a). However, the peak flow value shown in Table 3 is relatively low, especially with respect to that estimated by field surveys (about $90 \mathrm{~m}^{3} \mathrm{~s}^{-1}$, according to CFM 2015a). This value is achieved without any calibration and with dry ICs, but it could change significantly by modifying few key parameters (e.g., in the simulation with the highest precipitation input, increasing the initial moisture of the first soil layer of the $50 \%$ and reducing the infiltration factor REFKDT by only 0.4 , peak flow would increase to $30 \mathrm{~m}^{3} \mathrm{~s}^{-1}$ ). However, given the great uncertainty with observations, any calibration would be rather speculative, and would not add essential information to the main outcome of this experiment.

\section{b. Case study II (31 October-2 November 2015)}

The two catchments on which the hydrological analysis is focused are located close to the northern (the Ancinale River catchment) and southern (the Bonamico Creek catchment) tips of the area most affected by heavy rainfall. Since these catchments are about $60 \mathrm{~km}$ apart, the performance of the rainfall simulation may be quite different in the two basins. Specifically for case study II, some features clearly highlighted by the analysis of the simulated precipitation (e.g., more abundant rainfall in the ERA5-driven experiments, or low MOLOCH bias) are reproduced fairly well in the simulations across the Ancinale River catchment (Figs. 10a-d),

TABLE 3. Accumulated averaged precipitation between 0300 and 0800 UTC 12 Aug 2015, in Citrea Creek catchment and corresponding peak flow intensity and timing for the eight simulations.

\begin{tabular}{|c|c|c|c|c|c|c|c|c|}
\hline & \multicolumn{4}{|c|}{ WRF } & \multicolumn{4}{|c|}{ MOLOCH } \\
\hline & EraI & EraI_Med & Era5 & Era5_Med & EraI & EraI_Med & Era5 & Era5_Med \\
\hline $\begin{array}{l}\text { Accumulated precipitation between } 0300 \\
\text { and } 0800 \text { UTC }(\mathrm{mm})\end{array}$ & 3.6 & 65.6 & 0.8 & 77.0 & 6.7 & 35.6 & 0.4 & 3.2 \\
\hline Peak flow $\left(\mathrm{m}^{3} \mathrm{~s}^{-1}\right)$ & 2.138 & 5.300 & 3.374 & 13.538 & 0.004 & 1.955 & 0.496 & 0.007 \\
\hline Peak flow time (UTC) & 0500 & 0700 & 0700 & 0500 & 0300 & 0800 & 0300 & 0300 \\
\hline
\end{tabular}




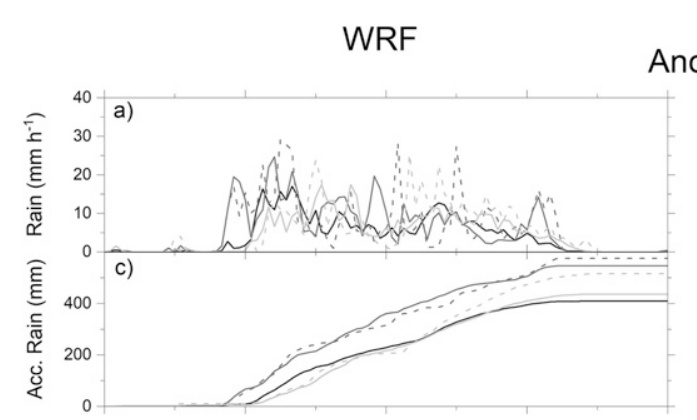

Ancinale
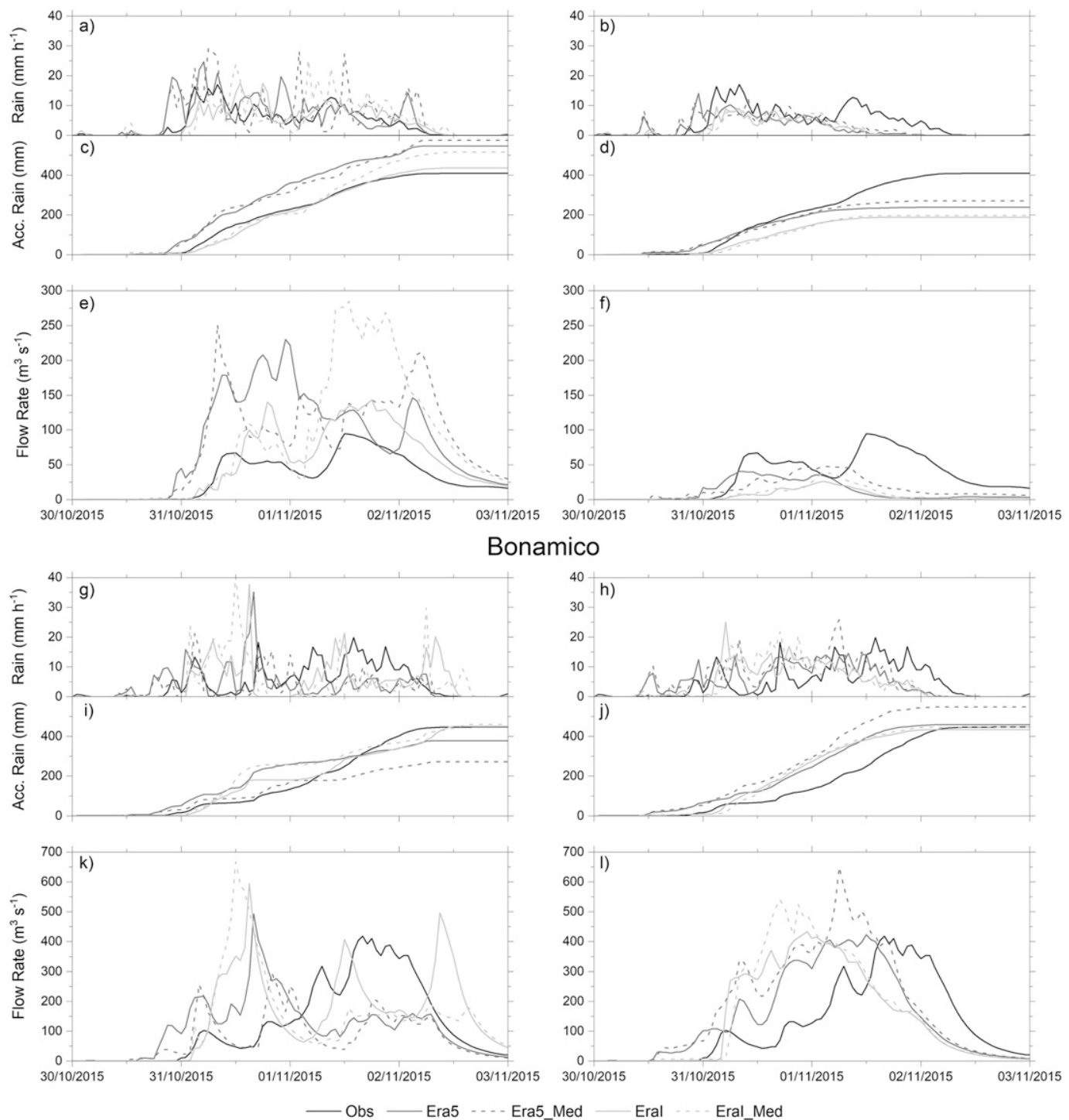

FIG. 10. Hourly rainfall and accumulated averaged precipitation in the (a)-(d) Ancinale and (g)-(j) Bonamico catchment areas, and (e),(f),(k),(l) corresponding hydrographs concerning the case study II (31 Oct-2 Nov 2015), for the (left) WRF and (right) MOLOCH simulations. Concerning flow rate, "Obs" refers to modeled discharge driven by observations.

but they are not so evident in the Bonamico Creek catchment (Figs. 10g-j). It is worth noting that the present analysis highlights only the shortcomings and uncertainties of the atmospheric components/models of the downscaling process, because the reference discharge simulation is obtained by the calibrated WRFHydro model based on observed precipitation, thus in a "perfect hydrological model" framework.

Figures 10a-f show that the simulation of rainfall fields and the following hydrological responses in the Ancinale River primarily depend upon the mesoscale model adopted. The rainfall field characteristics described in section $4 \mathrm{~b}$ through the statistical scores reflect on the hydrological discharges. For both models, ERA5 BCs lead to higher precipitation than ERA-Interim BCs. This leads to excessive overestimation in WRF, but improves MOLOCH estimates; to a minor extent, warmer Medspiration SST fields increase rainfall. Of course, the hydrological impact depends on meteorological inputs, but there is no a straightforward correlation. A major role is played by the antecedent soil moisture conditions before the most intense phase of the 
event, as well as by the spatial distribution of the rainfall, which is not shown by the average precipitation in Fig. 10: the highest peak flow occurs with the WRF simulation driven by ERA-Interim and the Medspiration SST field (even though this simulation does not provide the highest accumulated precipitation) because the most intense rainfall occurs when the catchment is already moistened by previous precipitation. In general, the ratio of the runoff/rainfall volumes increases linearly with the amount of rainfall predicted (it is $24 \%$ for the hydrological model driven by observations, $43 \%$ for the WRF ERA5-driven simulation with the Medspiration SST fields, 9\% for the MOLOCH ERA-Interim-driven simulation with native SST fields). Despite the streamflow overestimation up to almost $250 \%$, WRF-driven hydrographs are well correlated to that driven by observations. The highest correlation is attained for the WRF simulation driven by ERA-Interim and native SST field (Pearson coefficient $r=0.91$ ). On the other hand, the rainfall predicted by MOLOCH is too weak (consistently with the low FBI previously shown) for the catchment to respond and reproduce the second most intense peak flow on 1 November 2015.

In the Bonamico Creek catchment, the mesoscale models are closer in terms of precipitation amount (Figs. $10 \mathrm{~g}-\mathrm{j}$ ), and the effects of the different BCs are weaker and contrasting: ERA5 BCs slightly reduce (increase) the total rainfall amount with WRF $(\mathrm{MOLOCH})$; this effect is further amplified using the Medspiration SST fields. Peak flows intensities are close to the reference hydrograph, but they occur too early. Therefore, the simulated hydrographs (Figs. 10k-1) are not highly correlated to the reference one ( $r$ is higher than 0.6 only with the two MOLOCH ERA5-driven simulations), but the simulated mean discharges range around $80 \%-120 \%$ of the reference discharge (except the WRF and MOLOCH ERA5-driven simulations with Medspiration SST fields, being $63 \%$ and $146 \%$, respectively). MOLOCH simulations with native SST fields lead to peak flow values exceptionally close to that of the reference discharge, though occurring earlier than observed (17 and $4 \mathrm{~h}$ before, with ERA-Interim and ERA5 BCs, respectively). The ratio of the runoff/rainfall volumes is generally only slightly higher than the value achieved with observations of $70 \%$, ranging from $70 \%$ to $88 \%$.

Overall, all the eight modeling chains applied to the Ancinale catchment show that the simulation of the hydrological impact is mainly biased by overestimation or underestimation of rainfall, while the main issue with the Bonamico basin is given by an early onset of the event. Such different responses occur within a relatively short distance in space, highlighting that within the same domain very different modeling issues can arise, which affect the meteorological outputs and are emphasized by the hydrological responses. Indeed, in both basins, the skill of the hydrographs strongly depends on the spatial and temporal accuracy of the modeled rainfall, given the short interval between the rain and discharge peaks in such small catchments. Finally, these hydrological results clearly show that the analysis of rainfall statistical indexes provides an evaluation of the meteorological model behavior averaged over the entire region, but the high spatial variability of the rainfall fields may produce contrasting results in small basins, even if closer.

\section{c. Case study III (25-26 November 2016)}

This case study mainly affects the Bonamico Creek catchment (observed averaged accumulated precipitation of $180 \mathrm{~mm}$ during the event, Figs. $11 \mathrm{~g}-\mathrm{j}$ ), while the Ancinale River catchment is only marginally affected (50 mm, Figs. 11a-d). In agreement with the FBI analysis (Figs. 8a,b), simulated precipitation always underestimates observations, especially if ERA5 BCs are used (except for the Bonamico catchment with MOLOCH, where the strongest underprediction is achieved using ERA-Interim BCs). Notwithstanding such underprediction, the highest peak flow in the Ancinale River largely exceeds that of the reference hydrograph and is always produced by ERA-Interim-driven configurations, either with native or Medspiration SST fields, which provide higher intensity on 25 November afternoon (Figs. 11e,f). These simulations concentrate the rainfall in a few hours, thus producing a sharp hydrological response in the catchment.

In the Bonamico catchment, rainfall underprediction expresses itself in the hydrographs (Figs. 11k,l), where the simulated mean flow is from $10 \%$ (with ERA-Interimdriven MOLOCH simulation with Medspiration SST fields) to $42 \%$ (with the ERA-Interim-driven WRF simulation with native SST fields) of the reference discharge. The simulated peak flow of the latter is quite close to that of the reference hydrograph (about 98\%), although delayed by $17 \mathrm{~h}$. Interestingly, the ERA5driven WRF simulation with native SST fields is well correlated $(r=0.80)$, even though it also strongly underestimates the reference hydrograph.

This last case study also confirms the foremost importance of accurate rainfall simulations for hydrological impact assessment in small catchments, particularly the timing and the duration of the rainfall. It also highlights that the potential benefit provided by improved BCs can be ineffective with high-resolution dynamical downscaling aimed at analyzing impacts at the catchment scale. Unlike the previous case study, here the main issue is always precipitation underprediction 

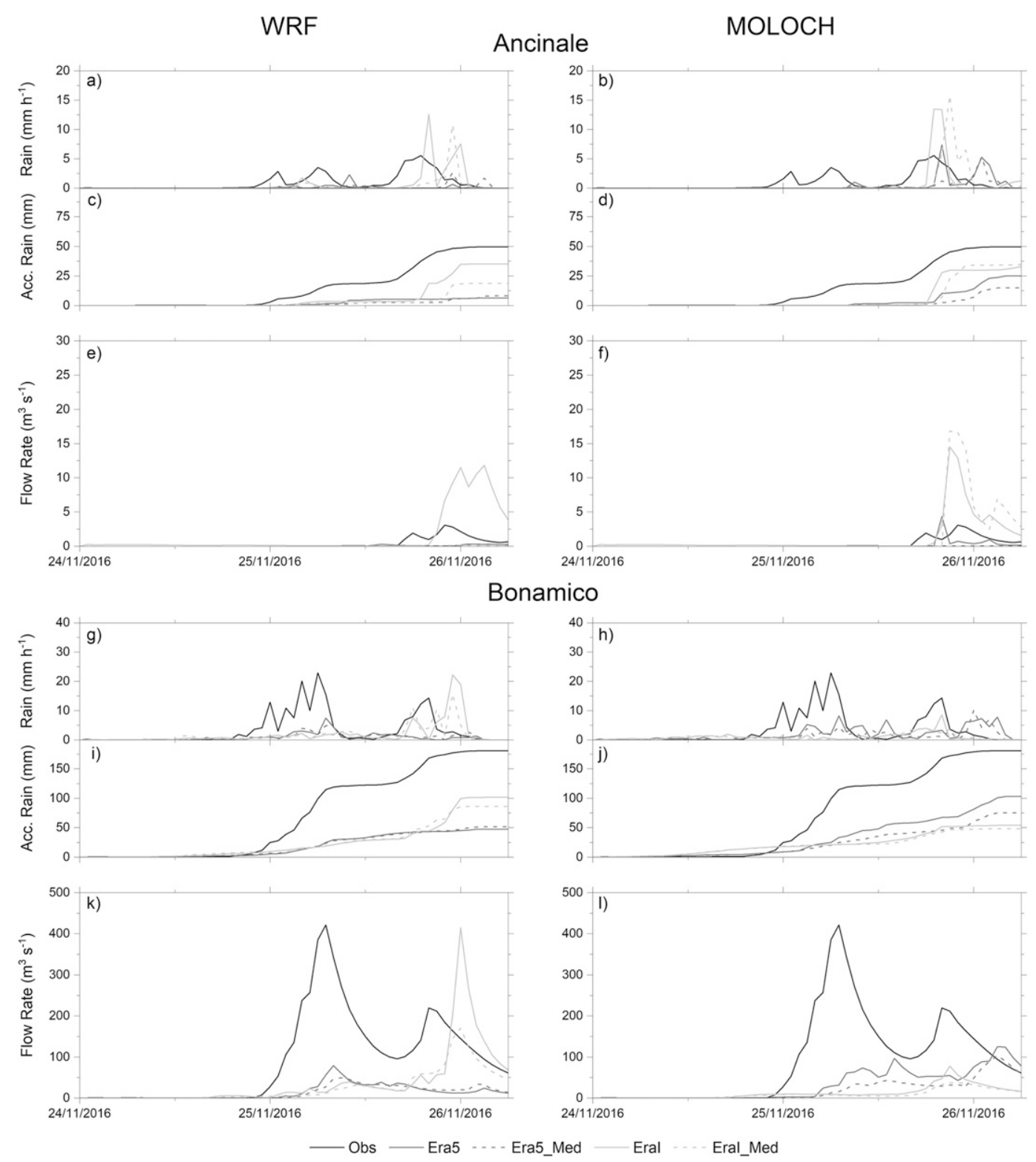

FIG. 11. As in Fig. 10, but for case study III (25-26 Nov 2016).

within the basin, which is not solved either by applying ERA5 BCs or higher resolution SST data. However, it is noteworthy that all simulations capture the main features of the precipitation pattern, less rainfall (and consequently, lower flow rate) in the Ancinale area and more (even though not enough) in the Bonamico catchment.

\section{Conclusions}

Dynamical downscaling of two global reanalyses has been performed by applying two state-of-the-art mesoscale modeling systems, for three severe weather events that recently affected southern Italy. Moreover, a distributed hydrological model has been applied at the end of each meteorological modeling chain to compute the discharge in some relevant basins and thus reconstruct the hydrological impact of these events. This exercise represents a preliminary and necessary step aimed at evaluating if, and to what extent, it is possible to apply convection-resolving models, driven by reanalyses, to reconstruct hydrometeorological hazardous events at the regional scale, over a territory characterized by very complex orography such as the Calabria region of southern Italy. To this end, the effects of different initial and boundary conditions, including SSTs, have 
been evaluated in terms of rainfall and discharge simulations.

On the whole, reanalyses are able to describe the synoptic environment in which the precipitating systems develop and it is evident how the higher resolution of ERA5 allows a better description of several mesoscale dynamically important features in the Mediterranean basin, like low-level convergence and interaction between flow and orographic chains. However, although ERA5 provides precipitation analyses closer to observations than ERA-Interim, neither reanalyses realistically reproduce the intense rainfall affecting the mountainous Calabria region with complex distribution patterns and very high local intensity. Thus, dynamical downscaling is required.

WRF and MOLOCH simulations differ from each other and both are sensitive to the initial and boundary conditions employed. On the one hand, the analysis of the high-resolution simulations, in terms of accumulated rainfall, shows that the main characteristics of each event, in particular, the considerable intensity of precipitation, its strong correlation with the underlying orography and its highly localized nature, are accurately reproduced by both models, and add significant detail to the representation of the reanalysis rainfall field. On the other hand, moving to smaller scales, forecast uncertainties emerge and are pointed out by the statistical scores.

For the quantitative evaluation of model simulations, different skill scores are analyzed in order to overcome, at least partially, the double-penalty problem (Rossa et al. 2008) that affects high-resolution model validation, but also to gain information on different aspects of rainfall field accuracy. In particular, the FSS indicates that both WRF and MOLOCH can reproduce the location of the most intense precipitation, and model simulations turn out to be generally useful at a spatial scale of about $10-15 \mathrm{~km}$, sometimes even smaller. However, hydrological results show that this may not be enough to ensure accurate discharge simulations, due to the limited size of the analyzed basins, to local hydrological processes (e.g., soil moisture conditions) and also to simulated rainfall uncertainty in both space and time. The latter turns out to be related more to the mesoscale model than to the reanalysis adopted as initial/boundary conditions, since WRF and MOLOCH do not show systematic behavior in this respect. Moreover, the relative importance of convective activity in enhancing the precipitation intensity in all three case studies adds uncertainty to the model predictions: the more active the convection, the larger the differences among simulations, even driven by similar BCs. This large uncertainty associated with the rainfall simulation acts as noise that can overcome the
BCs signal provided by the different reanalyses. Thus, no systematic behavior in the simulations of the two different modeling systems is detected, and no clear evidence is provided about the benefit of ERA5 IC and BCs for this kind of application at small spatial scales. The experiments do not support expected improvement in the downscaling of ERA5, compared to ERA-Interim. Moreover, the use of high-resolution SST fields to initialize mesoscale models shows even weaker influence than that observed by switching from ERA-Interim to ERA5, and does not systematically lead to more accurate simulations.

These results point out the limit of a deterministic approach to simulating extreme rainfall events, due to large uncertainties affecting the forecasts, especially at the local scales appropriate for most hydrological applications. Dealing with very small catchments, as those affected by the analyzed events, makes the accurate simulation of rainfall very challenging, and errors are amplified by subsequent discharge simulations. Indeed, it is not enough to correctly simulate the evolution of the areal (i.e., domain scale) averaged precipitation since the hydrological response shows large sensitivity to the exact location (on the order of few kilometers) and to the timing of the rainfall, which greatly affects the evolution of the soil moisture conditions.

Nevertheless, notwithstanding growing uncertainties with increasing downscaling resolution, each case study demonstrates accurate results through a modeling chain that ends at hydrological response in small and very small catchments. This suggests that, even for these applications, it would be useful to convey and exploit the information provided by downscaling different reanalyses with different mesoscale models to build an ensemble of precipitation scenarios that better describe the analyzed event (e.g., Pappenberger et al. 2005; Zappa et al. 2010), or even to use the multiple members of an ERA5 ensemble to improve the downscaling information. This approach would better exploit the potential of ERA5 to cope with the uncertainty and further manage it into the hydrological prediction.

Acknowledgments. We thank the "Centro Funzionale Multirischi" of the Calabrian Regional Agency for the Protection of the Environment for providing the observed precipitation data and the Italian National Civil Protection "Centro Funzionale Centrale Rischio Meteo-idrogeologico e Idraulico" for providing radar data. Both rainfall and radar data are delivered, upon request, by the "Centro Funzionale Multirischi-ARPACAL" (http://www.cfd.calabria.it/) and the Italian National Civil Protection "Centro Funzionale Centrale Rischio Meteo-idrogeologico e Idraulico" (http:// www.protezionecivile.gov.it/home), respectively. L. Furnari 
acknowledges support from the Programme "POR Calabria FSE/FESR 2014/2020_Mobilità internazionale di Dottorandi e Assegnisti di ricerca/Ricercatori di Tipo A, Actions 10.5.6 and 10.5.12." This work is a contribution to the HyMeX international programme. Finally, we are very grateful to Gregory J. Carbone (University of South Carolina) and Karen Beidel for kindly and patiently reviewing the manuscript.

\section{REFERENCES}

Aceto, L., T. Caloiero, A. A. Pasqua, and O. Petrucci, 2016: Analysis of damaging hydrogeological events in a Mediterranean region (Calabria). J. Hydrol., 541, 510-522, https://doi.org/10.1016/ j.jhydrol.2015.12.041.

Avolio, E., and S. Federico, 2018: WRF simulations for a heavy rainfall event in southern Italy: Verification and sensitivity tests. Atmos. Res., 209, 14-35, https://doi.org/10.1016/j.atmosres. 2018.03.009.

- O. Cavalcanti, L. Furnari, A. Senatore, and G. Mendicino, 2019: Brief communication: Preliminary hydro-meteorological analysis of the flash flood of 20 August 2018 in Raganello Gorge, southern Italy. Nat. Hazards Earth Syst. Sci., 19, 1619-1627, https://doi.org/10.5194/nhess-19-1619-2019.

Bauer, H., T. Weusthoff, M. Dorninger, V. Wulfmeyer, T. Schwitalla, T. Gorgas, M. Arpagaus, and K. Warrach-Sagi, 2011: Predictive skill of a subset of models participating in D-PHASE in the COPS region. Quart. J. Roy. Meteor. Soc., 137, 287-305, https://doi.org/ 10.1002/qj.715.

Buzzi, A., M. D'Isidoro, and S. Davolio, 2003: A case study of an orographic cyclone south of the Alps during the MAP SOP. Quart. J. Roy. Meteor. Soc., 129, 1795-1818, https://doi.org/ 10.1256/qj.02.112.

, S. Davolio, P. Malguzzi, O. Drofa, and D. Mastrangelo, 2014: Heavy rainfall episodes over Liguria of autumn 2011: Numerical forecasting experiments. Nat. Hazards Earth Syst. Sci., 14, 1325-1340, https://doi.org/10.5194/nhess-14-1325-2014.

CFM, 2015a: Rapporto speditivo di evento metopluviometrico del 12 agosto 2015 (in Italian). Centro Funzionale Multirischi della Calabria Tech. Rep., 17 pp., https://www.cfd.calabria.it// DatiVari/Pubblicazioni/rapporto\%20di\%20evento\%2012\% 20agosto.pdf.

_, 2015 b: Rapporto speditivo di evento metopluviometrico del 30 ottobre - 2 novembre 2015 (in Italian). Centro Funzionale Multirischi della Calabria Tech. Rep., 36 pp., https://www.cfd.calabria.it//DatiVari/Pubblicazioni/rapporto\% 20di\%20evento\%2030\%20ottobre-2\%20novembre2015.pdf.

, 2016: Rapporto speditivo di evento metopluviometrico del 25-26 novembre 2016 (in Italian). Centro Funzionale Multirischi della Calabria Tech. Rep., 31 pp., https://www.cfd.calabria.it// DatiVari/Pubblicazioni/rapporto\%20di\%20evento\%202526\%20novembre2016.pdf.

Chen, S. H., and W.-Y. Sun, 2002: A one-dimensional time dependent cloud model. J. Meteor. Soc. Japan, 80, 99-118, https://doi.org/10.2151/jmsj.80.99.

Chiaravalloti, F., and S. Gabriele, 2009: Vibo Valentia flood and MSG rainfall evaluation. Atmos. Res., 93, 286-294, https:// doi.org/10.1016/j.atmosres.2008.10.027.

Clark, P., N. Roberts, H. Lean, S. P. Ballard, and C. CharltonPerez, 2016: Convection-permitting models: A step-change in rainfall forecasting. Meteor. Appl., 23, 165-181, https://doi.org/ 10.1002/met.1538.
Coppola, E., and Coauthors, 2018: A first-of-its-kind multi-model convection permitting ensemble for investigating convective phenomena over Europe and the Mediterranean. Climate Dyn., 55, 3-34, https://doi.org/10.1007/s00382-018-4521-8.

Davolio, S., F. Silvestro, and P. Malguzzi, 2015: Effects of increasing horizontal resolution in a convection-permitting model on flood forecasting: The 2011 dramatic events in Liguria, Italy. J. Hydrometeor., 16, 1843-1856, https://doi.org/ 10.1175/JHM-D-14-0094.1.

—, R. Henin, P. Stocchi, and A. Buzzi, 2017: Bora wind and heavy persistent precipitation: Atmospheric water balance and role of air-sea fluxes over the Adriatic Sea. Quart. J. Roy. Meteor. Soc., 143, 1165-1177, https://doi.org/10.1002/qj.3002.

Dee, D. P., and Coauthors, 2011: The ERA-Interim reanalysis: Configuration and performance of the data assimilation system. Quart. J. Roy. Meteor. Soc., 137, 553-597, https://doi.org/ 10.1002/qj.828.

Ducrocq, V., and Coauthors, 2014: HyMeX-SOP1: The field campaign dedicated to heavy precipitation and flash flooding in the northwestern Mediterranean. Bull. Amer. Meteor. Soc., 95, 1083-1100, https://doi.org/10.1175/BAMS-D-12-00244.1.

Dudhia, J., 1989: Numerical study of convection observed during the winter monsoon experiment using a mesoscale two-dimensional model. J. Atmos. Sci., 46, 3077-3107, https://doi.org/10.1175/ 1520-0469(1989)046<3077:NSOCOD>2.0.CO;2.

Federico, S., C. Bellecci, and M. Colacino, 2003: Quantitative precipitation of the Soverato flood: The role of orography and surface fluxes. Nuovo Cimento, 26, 7-22.

—, E. Avolio, C. Bellecci, A. Lavagnini, M. Colacino, and R. L. Walko, 2008: Numerical analysis of an intense rainstorm occurred in southern Italy. Nat. Hazards Earth Syst. Sci., 8, 19-35, https://doi.org/10.5194/nhess-8-19-2008.

Fiori, E., A. Comellasa, D. Molini, N. Rebora, F. Siccardi, D. Gochis, S. Tanelli, and A. Parodi, 2014: Analysis and hindcast simulations of an extreme rainfall event in the Mediterranean area: The Genoa 2011 case. Atmos. Res., 138, 13-29, https://doi.org/10.1016/j.atmosres.2013.10.007.

Flaounas, S., L. Fita, K. Lagouvardos, and V. Kotroni, 2019: Heavy rainfall in Mediterranean cyclones, Part II: Water budget, precipitation efficiency and remote water sources. Climate Dyn., 53, 2539-2555, https://doi.org/10.1007/s00382019-04639-x.

Gascòn, E., S. Laviola, A. Merino, and M. M. Miglietta, 2016: Analysis of a localized flash-flood event over the central Mediterranean. Atmos. Res., 182, 256-268, https://doi.org/ 10.1016/j.atmosres.2016.08.007.

Gochis, D. J., W. Yu, and D. N. Yates, 2015: The WRF-Hydro model technical description and user's guide, version 3.0. NCAR Tech. Doc., 123 pp., https://ral.ucar.edu/sites/default/ files/public/WRF_Hydro_User_Guide_v3.0_CLEAN.pdf.

Grell, G. A., L. Schade, R. Knoche, A. Pfeiffer, and J. Egger, 2000: Nonhydrostatic climate simulations of precipitation over complex terrain. J. Geophys. Res., 105, 29595-29 608, https:// doi.org/10.1029/2000JD900445.

Hennermann, K., and P. Berrisford, 2018: What are the changes from ERA-Interim to ERA5? ECMWF, https://confluence.ecmwf.int/ pages/viewpage. action?pageId $=74764925$.

Hersbach, H., and D. Dee, 2016: ERA5 reanalysis is in production. ECMWF Newsletter, No. 147, ECMWF, Reading, United Kingdom, 7, https://www.ecmwf.int/en/newsletter/147/news/ era5-reanalysis-production.

Hong, S.-Y., and M. Kanamitsu, 2014: Dynamical downscaling: Fundamental issues from an NWP point of view and 
recommendations. Asia-Pac. J. Atmos. Sci., 50, 83-104, https:// doi.org/10.1007/s13143-014-0029-2.

Janjić, Z. I., 1994: The step-mountain Eta coordinate model: Further developments of the convection, viscous sublayer, and turbulence closure schemes. Mon. Wea. Rev., 122, 927-945, https://doi.org/10.1175/1520-0493(1994)122<0927:TSMECM> 2.0.CO;2.

Kain, J. S., 2004: The Kain-Fritsch convective parameterization: An update. J. Appl. Meteor., 43, 170-181, https://doi.org/ 10.1175/1520-0450(2004)043<0170:TKCPAU>2.0.CO;2.

Khodayar, S., and Coauthors, 2016: A seamless weather-climate multi-model intercomparison on the representation of a high impact weather event in the western Mediterranean: HyMeX IOP12. Quart. J. Roy. Meteor. Soc., 142, 433-452, https:// doi.org/10.1002/qj.2700.

Li, L., M. Pontoppidan, S. Sobolowski, and A. Senatore, 2020: The impact of initial conditions on convection-permitting simulations of a flood event over complex mountainous terrain. Hydrol. Earth Syst. Sci., 24, 771-791, https://doi.org/10.5194/ hess-24-771-2020.

Llasat, M. C., M. Llasat-Botija, O. Petrucci, A. A. Pasqua, J. Rosselló, F. Vinet, and L. Boissier, 2013: Towards a database on societal impact of Mediterranean floods within the framework of the HYMEX project. Nat. Hazards Earth Syst. Sci., 13, 1337-1350, https://doi.org/10.5194/nhess-13-13372013.

Malguzzi, P., G. Grossi, A. Buzzi, R. Ranzi, and R. Buizza, 2006: The 1966 'century' flood in Italy: A meteorological and hydrological revisitation. J. Geophys. Res., 111, D24106, https:// doi.org/10.1029/2006JD007111.

Mass, C. F., D. Ovens, K. Westrick, and B. A. Colle, 2002: Does increasing horizontal resolution produce more skillful forecasts? Bull. Amer. Meteor. Soc., 83, 407-430, https://doi.org/ 10.1175/1520-0477(2002)083<0407:DIHRPM>2.3.CO;2.

Mellor, G. L., and T. Yamada, 1982: Development of a turbulence closure model for geophysical fluid problems. Rev. Geophys., 20, 851-875, https://doi.org/10.1029/RG020i004p00851.

Merchant, C. J., M. J. Filipiak, P. Le Borgne, H. Roquet, E. Autret, J.F. Piolle, and S. Lavender, 2008: Diurnal warm-layer events in the western Mediterranean and European shelf seas. Geophys. Res. Lett., 35, L04601, https://doi.org/10.1029/2007GL033071.

Mlawer, E. J., S. J. Taubman, P. D. Brown, M. J. Iacono, and S. A. Clough, 1997: Radiative transfer for inhomogeneous atmospheres: RRTM, a validated correlated-k model for the longwave. J. Geophys. Res., 102, 16 663-16 682, https:// doi.org/10.1029/97JD00237.

Morcrette, J. J., H. W. Barker, J. N. S. Cole, M. J. Iacono, and R. Pincus, 2008: Impact of a new radiation package, McRad, in the ECMWF integrated forecasting system. Mon. Wea. Rev., 136, 4773-4798, https://doi.org/10.1175/2008MWR2363.1.

Pappenberger, F., K. J. Beven, N. M. Hunter, P. D. Bates, B. T. Gouweleeuw, J. Thielen, and A. P. J. de Roo, 2005: Cascading model uncertainty from medium range weather forecasts (10 days) through a rainfall-runoff model to flood inundation predictions within the European Flood Forecasting System (EFFS). Hydrol. Earth Syst. Sci., 9, 381-393, https://doi.org/ 10.5194/hess-9-381-2005.

Polemio, M., and O. Petrucci, 2012: The occurrence of floods and the role of climate variations from 1880 in Calabria (southern Italy). Nat. Hazards Earth Syst. Sci., 12, 129-142, https:// doi.org/10.5194/nhess-12-129-2012.

Pontoppidan, M., J. Reuder, S. Mayer, and E. W. Kolstad, 2017: Downscaling an intense precipitation event in complex terrain:
The importance of high grid resolution. Tellus, 69A, 1271561, https://doi.org/10.1080/16000870.2016.1271561.

Prein, A. F., and Coauthors, 2015: A review on regional convectionpermitting climate modeling: Demonstrations, prospects, and challenges. Rev. Geophys., 53, 323-361, https://doi.org/10.1002/ 2014RG000475.

Richard, E. A., A. Buzzi, and G. Zängl, 2007: Quantitative precipitation forecasting in the Alps: The advances achieved by the Mesoscale Alpine Programme. Quart. J. Roy. Meteor. Soc., 133, 831-846, https://doi.org/10.1002/qj.65.

Ritter, B., and J. F. Geleyn, 1992: A comprehensive radiation scheme for numerical weather prediction models with potential applications in climate simulations. Mon. Wea. Rev., 120, 303-325, https://doi.org/10.1175/1520-0493(1992)120<0303: ACRSFN $>2.0 . \mathrm{CO} ; 2$.

Roberts, N. M., 2008: Assessing the spatial and temporal variation in the skill of precipitation forecasts from an NWP model. Meteor. Appl., 15, 163-169, https://doi.org/10.1002/ met.57.

— , and H. W. Lean, 2008: Scale-selective verification of rainfall accumulations from high-resolution forecasts of convective events. Mon. Wea. Rev., 136, 78-97, https://doi.org/10.1175/ 2007MWR2123.1.

Robinson, I., J. F. Piolle, P. Leborgne, D. Poulter, C. Donlon, and O. Arino, 2012: Widening the application of AATSR SST data to operational tasks through the Medspiration Service. Remote Sens. Environ., 116, 126-139, https://doi.org/10.1016/ j.rse.2010.12.019.

Rossa, A., P. Nurmi, and E. Ebert, 2008: Overview of methods for the verification of quantitative precipitation forecasts. Precipitation: Advances in Measurement, Estimation and Prediction, S. Michaelides, Ed., Springer, 419-452, https://doi.org/10.1007/ 978-3-540-77655-0_16.

Schwartz, C. S., and Coauthors, 2009: Next-day convectionallowing WRF model guidance: A second look at 2-km versus 4-km grid spacing. Mon. Wea. Rev., 137, 3351-3372, https:// doi.org/10.1175/2009MWR2924.1.

Senatore, A., G. Mendicino, H. R. Knoche, and H. Kunstmann, 2014: Sensitivity of modeled precipitation to sea surface temperature in region with complex topography and coastlines: A case study for the Mediterranean. J. Hydrometeor., $\mathbf{1 5}$, 2370-2396, https://doi.org/10.1175/JHM-D-13-089.1.

, - D. J. Gochis, W. Yu, D. N. Yates, and H. Kunstmann, 2015: Fully coupled atmosphere-hydrology simulations for the central Mediterranean: Impact of enhanced hydrological parameterization for short and long time scales. J. Adv. Model. Earth Syst., 7, 1693-1715, https://doi.org/10.1002/ 2015MS000510.

—, L. Furnari, and G. Mendicino, 2020: Impact of highresolution sea surface temperature representation on the forecast of small Mediterranean catchments' hydrological response to heavy precipitation. Hydrol. Earth Syst. Sci., 24, 269-291, https://doi.org/10.5194/hess-24-269-2020.

Sinclair, S., and G. Pegram, 2005: Combining radar and rain gauge rainfall estimates using conditional merging. Atmos. Sci. Lett., 6, 19-22, https://doi.org/10.1002/asl.85.

Skamarock, W. C., and Coauthors, 2008: A description of the advanced research WRF version 3. NCAR Tech. Note NCAR/ TN-475+STR, 113 pp., https://doi.org/10.5065/D68S4MVH.

Skok, G., and N. Roberts, 2016: Analysis of fractions skill score properties for random precipitation fields and ECMWF forecasts. Quart. J. Roy. Meteor. Soc., 142, 2599-2610, https:// doi.org/10.1002/qj.2849. 
Stark, J. D., C. J. Donlon, M. J. Martin, and M. E. McCulloch, 2007: OSTIA: An operational, high resolution, real time, global sea surface temperature analysis system. Oceans 2007-Europe, Aberdeen, Scotland, IEEE, 1-4, https://doi.org/10.1109/ OCEANSE.2007.4302251.

Stocchi, P., and S. Davolio, 2017: Intense air-sea exchanges and heavy orographic precipitation over Italy: The role of Adriatic Sea surface temperature uncertainty. Atmos. Res., 196, 62-82, https://doi.org/10.1016/j.atmosres.2017.06.004.

Tewari, M., and Coauthors, 2004: Implementation and verification of the unified NOAH land surface model in the WRF model 20th Conf. on Weather Analysis and Forecasting/16th Conf. on Numerical Weather Prediction, Silver Spring, MD, Amer. Meteor. Soc., 14.2a, https://ams.confex.com/ams/84Annual/ techprogram/paper_69061.htm.

Verri, G., N. Pinardi, D. Gochis, J. Tribbia, A. Navarra, G. Coppini, and T. Vukicevic, 2017: A meteo-hydrological modelling system for the reconstruction of river runoff: The case of the Ofanto River catchment. Nat. Hazards Earth Syst. Sci., 17, 1741-1761, https://doi.org/10.5194/nhess-17-1741-2017.

Weusthoff, T., F. Ament, M. Arpagaus, and M. W. Rotach, 2010: Assessing the benefits of convection permitting models by neighborhood verification: Examples from MAP D-PHASE. Mon. Wea. Rev., 138, 3418-3433, https://doi.org/10.1175/ 2010MWR3380.1.
Wilks, S. D., 2006: Statistical Methods in the Atmospheric Sciences. 2nd ed. International Geophysics Series, Vol. 100, Academic Press, $648 \mathrm{pp}$

Yucel, I., A. Onen, K. Yilmaz, and D. J. Gochis, 2015: Calibration and evaluation of a flood forecasting system: Utility of numerical weather prediction model, data assimilation and satellite-based rainfall. J. Hydrol., 523, 49-66, https://doi.org/ 10.1016/j.jhydrol.2015.01.042.

Zampieri, M., P. Malguzzi, and A. Buzzi, 2005: Sensitivity of quantitative precipitation forecasts to boundary layer parameterization: A flash flood case study in the western Mediterranean. Nat. Hazards Earth Syst. Sci., 5, 603-612, https://doi.org/10.5194/nhess-5-603-2005.

Zappa, M., and Coauthors, 2010: Propagation of uncertainty from observing systems and NWP into hydrological models: COST731 working group 2. Atmos. Sci. Lett., 11, 83-91, https://doi.org/10.1002/asl.248.

Zeng, X., and A. Beljaars, 2005: A prognostic scheme of sea surface skin temperature for modeling and data assimilation. Geophys. Res. Lett., 32, L14605, https://doi.org/10.1029/2005GL023030.

Zsoter, E., H. Cloke, E. Stephens, P. de Rosnay, J. Muñoz-Sabater, C. Prudhomme, and F. Pappenberger, 2019: How well do operational numerical weather prediction setups represent hydrology? J. Hydrometeor., 20, 1533-1552, https://doi.org/ 10.1175/JHM-D-18-0086.1. 